\title{
1 Gli1 regulates the postnatal acquisition of peripheral nerve architecture
}

2 Brendan Zotter ${ }^{1}$, Or Dagan ${ }^{1}$, Jacob Brady ${ }^{1}$, Hasna Baloui ${ }^{2}$, Jayshree Samanta ${ }^{3}$ and James L.

3 Salzer ${ }^{1, *}$

$4{ }^{1 .}$ Department of Neuroscience and Physiology, Neuroscience Institute, NYU Langone Medical

5 Center, New York, NY, 10016, USA

6 2. Departments of Neuroscience and Clinical Neuroscience, Karolinska Institutet, Stockholm

7 17177, Sweden

8 3. Department of Comparative Biosciences, School of Veterinary Medicine, Stem Cell and

9 Regenerative Medicine Center, University of Wisconsin-Madison, Madison, WI, 53706, USA

10 * Correspondence: James L. Salzer, Department of Neuroscience and Physiology and the NYU

11 Neuroscience Institute, 435 E. 30 ${ }^{\text {th }}$ Street Rm 1123C, New York, NY, 10016, USA.

12 james.salzer@nyulangone.org

14 NUMBER OF PAGES: 64

15 NUMBER OF FIGURES: 12 Main, 2 Extended data figures, 1 Extended data video

16 NUMBER OF WORDS: 250 (Abstract), 973 (Introduction), 3343 (Discussion) 
19 The authors declare no competing financial interests.

20

\section{ACKNOWLEDGEMENTS}

22 The authors are grateful to the NYU Langone Health Microscopy Core for extensive assistance

23 with electron microscopy, to Warren J. Leonard (NIH-NHLBI) for generously providing the 24 Egr2 flox mouse line, to the NYU Rodent Genetic Engineering Core for their assistance with

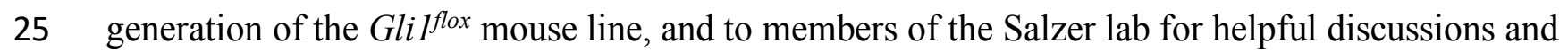
26 comments on the manuscript. This work was supported by NS103353 to B.Z. and NS100867 to 27 J.L.S.

28

\section{AUTHOR CONTRIBUTIONS}

30 Conceptualization, B.Z. and J.L.S.; Methodology, B.Z., O.D., H.B., and J.S.; Investigation, B.Z., 31 J.B., and O.D.; Writing - Original Draft, B.Z. and J.L.S.; Writing - Review \& Editing, B.Z., H.B., 32 J.S., and J.L.S.; Funding Acquisition, B.Z. and J.L.S.; Supervision, J.L.S. 


\section{ABSTRACT}

34 Peripheral nerves are organized into discrete cellular compartments. Axons, Schwann cells (SCs),

35 and endoneurial fibroblasts (EFs) reside within the endoneurium and are surrounded by the

36 perineurium - a cellular sheath comprised of layers of perineurial glia (PNG). SC secretion of

37 Desert Hedgehog (Dhh) regulates this organization. In Dhh nulls, the perineurium is deficient and

38 the endoneurium is subdivided into small compartments termed minifascicles. Human Dhh

39 mutations cause a peripheral neuropathy with similar defects. Here we examine the role of Gli1, a

40 canonical transcriptional effector of hedgehog signaling, in regulating peripheral nerve

41 organization. We identify PNG, EFs, and pericytes as Glil-expressing cells by genetic fate

42 mapping. Although expression of Dhh by SCs and Glil in target cells is coordinately regulated

43 with myelination, Glil expression unexpectedly persists in Dhh null EFs. Thus, Gli1 is expressed

44 in EFs non-canonically i.e., independent of hedgehog signaling. Gli1 and Dhh also have non-

45 redundant activities. In contrast to Dhh nulls, Gli1 nulls have a normal perineurium. Like Dhh

46 nulls, Gli1 nulls form minifascicles, which we show likely arise from EFs. Thus, Dhh and Gli1 are

47 independent signals: Gli1 is dispensable for perineurial development but functions cooperatively

48 with Dhh to drive normal endoneurial development. During development, Gli1 also regulates

49 endoneurial extracellular matrix production, nerve vascular organization, and has modest, non-

50 autonomous effects on SC sorting and myelination of axons. Finally, in adult nerves, induced

51 deletion of Gli1 is sufficient to drive minifascicle formation. Thus, Gli1 regulates the development

52 and is required to maintain the endoneurial architecture of peripheral nerves. 


\section{SIGNIFICANCE STATEMENT}

55 Peripheral nerves are organized into distinct cellular/ECM compartments: the epineurium,

56 perineurium and endoneurium. This organization, with its associated cellular constituents, are

57 critical for the structural and metabolic support of nerves and their response to injury. Here, we

58 show Gli1 - a transcription factor normally expressed downstream of hedgehog signaling - is

59 required for the proper organization of the endoneurium but not the perineurium. Unexpectedly,

60 Gli1 expression by endoneurial cells is independent of, and functions non-redundantly with,

61 Schwann Cell-derived Desert Hedgehog in regulating peripheral nerve architecture. These results

62 further delineate how peripheral nerves acquire their distinctive organization during normal

63 development and highlight mechanisms that may regulate their reorganization in pathologic

64 settings including peripheral neuropathies and nerve injury.

65

66 Keywords: peripheral nerve; Gli1; Schwann cell, myelination; endoneurium; perineurium; desert

67 hedgehog; fate mapping 
INTRODUCTION

Peripheral nerves are organized into distinct compartments (Figure 1A), i.e., the

70 endoneurium, the perineurium, and the epineurium. The organization of these compartments, and

71 their distinct cellular and extracellular matrix (ECM) composition, provides critical structural and

72 metabolic support of nerves and their function in action potential propagation. Cellular

73 components of the endoneurial compartment include axons, Schwann cells (SCs), and endoneurial

74 fibroblasts (EFs), which like SCs are neural crest derived (Joseph et al., 2004). EFs are interspersed

75 between the axon-SC units (Richard et al., 2012) and produce an intervening collagenous ECM.

76 Axon-SC units adopt one of two functional/morphological relationships. Individual SCs ensheath

77 multiple small, unmyelinated axons in separate pockets forming Remak fibers or sort larger axons

78 in a 1:1 relationship, which are then myelinated.

This mix of myelinated axons, Remak fibers, EFs, and ECM, are organized into fascicles,

80 which are enclosed by the perineurium. The latter is a cellular sheath and barrier comprised of

81 multiple layers of flattened perineurial glia (PNG), considered to be of neural ectodermal origin

82 (Kucenas et al., 2008; Clark et al., 2014). Finally, PNG-bounded nerve fascicles are further

83 surrounded by the epineurium, consisting of scattered fibroblasts and irregular bundles of collagen

84 fibrils. The epineurium is the outermost sheath that anchors fascicles to each other and to the

85 surrounding mesenchyme (Burkel, 1967). This multilayered fascicular structure provides

86 structural support that limits mechanical strain on axons and SCs while allowing nerves to remain

87 flexible during limb movement (Flores et al., 2000).

The epineurium also contains a plexus of blood vessels, the vasa nervorum, that penetrates

89 the perineurium at regular intervals to provide metabolic support to the endoneurium (Bell and

90 Weddell, 1984a). These various components create an immune privileged environment for axon- 
91 SC units (Peltonen et al., 2013). In particular, PNG form tight junctions, creating a perineurial

92 barrier to the invasion of toxins and pathogens (Kristensson and Olsson, 1971). Tight junctions

93 also form between ECs of endoneurial capillaries, constituting the blood nerve barrier (BNB)

94 (Olsson, 1968).

95 The molecular signals that underlie development of this complex organization, and 96 coordinate assembly of its various components, are incompletely understood. The ensheathment

97 fate of axons, i.e., whether they are myelinated or organize as Remak bundles, is regulated by

98 threshold levels of axonal Neuregulin, together with other signals on the axon and SC basal lamina

99 (Salzer, 2015; Feltri et al., 2016). These signals converge to upregulate a series of SC transcription

100 factors culminating in the expression of Egr2, the master regulator of the SC myelinating 101 phenotype (Topilko et al., 1994). Egr2 controls expression of the structural and metabolic genes 102 necessary for myelination.

103 Egr2 also directly upregulates expression of Desert Hedgehog (Dhh) by myelinating SCs

104 (mSCs) (Jang et al., 2006). Dhh is known to regulate peripheral nerve organization (Parmantier et 105 al., 1999). Knockouts of Dhh in mice (Parmantier et al., 1999) or mutations of Dhh in patients 106 (Umehara et al., 2000; Baldinotti et al., 2018) result in defective development of the perineurium 107 and epineurium. Loss of Dhh also results in the aberrant formation of minifascicles (MFs), which 108 are small compartments within the endoneurium enclosed by cellular sheaths. MFs are also 109 observed in a number of animal models where SC myelination is impaired, including those with 110 significant reductions of Egr2 and Dhh expression (Darbas et al., 2004; Monk et al., 2011). The 111 cell(s) of origin, the mechanisms of MF formation, and their function remain unknown. Both PNG 112 and EFs have been considered to be candidates to form the MF sheaths (Bunge et al., 1989; 113 Parmantier et al., 1999). 

and McMahon, 2001). All three Hh proteins bind to the Patched (Ptc) receptor on target cells to

117 activate a highly conserved signaling cascade mediated by the co-receptor Smoothened (Smo) and

118 the Gli family of transcription factors (Gli1/2/3) (Briscoe and Thérond, 2013). In the absence of

119 Hh, Ptc tonically inhibits Smo activity and both Gli2 and 3 are constitutively cleaved and function 120 as transcriptional repressors (Gli2R, Gli3R). Hh binding to Ptc relieves its inhibition of Smo, 121 blocking cleavage and resulting in full-length Gli2 and Gli3, which now function as transcriptional 122 activators (Gli2A, Gli3A). Among their transcriptional targets is Gli1 - itself a late transcriptional 123 effector of the Hh pathway (Wilson and Chuang, 2010). Mice that lack Gli1 alone do not exhibit 124 any evident phenotype, likely reflecting compensation by Gli2 (Park et al., 2000).

126 Moreover, Gli1 expression is considered a sensitive transcriptional readout of Hh pathway activity

127 (Ahn and Joyner, 2004; Dessaud et al., 2008); it is therefore a candidate to both report and mediate 128 Dhh activity in peripheral nerves. However, it is also known that in some settings Gli1 expression 129 is driven via non-canonical pathways, i.e., independent of Hh/Ptc/Smo (Dennler et al., 2007; Po et 130 al., 2017; Hasan et al., 2020).

131 Here, we used fate mapping to identify EFs, PNG, and pericytes as Gli1-expressing cells 132 in the adult PNS. Gli1 knockout mice recapitulate the MF formation seen in Dhh knockouts, but 133 in contrast have a normal perineurium. We show MFs likely initially assemble from EFs that 134 proliferate and morphologically differentiate in the absence of Gli1. Surprisingly, the EFs that 135 form MFs in Dhh knockouts persistently express Gli1. These latter results strongly suggest Gli1 136 expression in EFs is non-canonical and that it is required together with canonical Dhh signaling to 
137 drive normal development of the endoneurium - as loss of either pathway results in MF assembly.

138 Our findings also implicate Gli1 expression in EFs in ECM production, nerve vascular

139 organization, and modulating the fine structure of axon-SC units. Finally, induced deletion of Gli1

140 drives MF formation in healthy adult nerves. Together, these results implicate Gli1 in regulating

141 both the development and maintenance of peripheral nerve architecture. 


\section{MATERIALS AND METHODS}

Mouse husbandry

All animal work was conducted under an approved animal protocol and in accordance with the guidelines of the Institutional Animal Care and Use Committee of the New York University School of Medicine. Mice were housed in a temperature- and humidity-controlled vivarium on a 12-hr light-dark cycle with free access to food and water. The following strains were used: Gli1 $^{\text {CreERT2 }}$ (Jax \# 007913), R26 $6^{\text {FSF-CAG-EGFP }}$ (RCE, Jax \# 032037), R26 $6^{\text {FSF-LSL-tdTomato }}$ (Ai9, Jax \# 007909), Gli1 ${ }^{\text {nLacZ }}(\operatorname{Jax} \# 008211)$, Gli2 $^{\text {nLacZ }}\left(\mathrm{Jax} \#\right.$ 007922), R26 $6^{\text {FSF-FLAG-Gli1 }}$ (Rosa-Gli1, Jax \#

013123), Dhh/- (Jax \# 002784), MPZ-cre (Jax \# 017927), Egr2flox (Generous gift of W.J. Leonard,

NHLBI). For lineage tracing of hedgehog-responsive cells, Gli1 $1^{\text {CreERT2 }}$ mice were crossed to either

RCE or Ai9 reporter lines. To generate Gli1 null mice, Gli ${ }^{\text {CreERT2/+ }}$ and Gli ${ }^{\text {nLacZ }}$ mice were crossed to generate Gli1 ${ }^{\text {CreERT2/nLacZ }}$ compound heterozygotes. For genetic gain of function studies, Gli1 ${ }^{\text {CreERT2/+ }}$ were crossed with $R 26^{\text {FSF-FLAG-Glil }}$.

To generate Egr2 conditional knockouts, P0-cre and Egr $2^{f l o x}$ were crossed. These animals movement. With supportive care (i.e., nutrient-supplemented gelatin food and presence of littermates for grooming), knockouts survived up to 3 months or longer but were euthanized for humane reasons once they were unable to ambulate using their forelimbs.

\section{Generation of Gli1 $^{\text {Flox }}$ mice}

The targeting vector, containing exons 5-9 of the endogenous Gli1 locus flanked by LoxP 
stem cells by the NYU Rodent Genetic Engineering Laboratory. After selection with G418

171 by targeted sequencing to confirm fidelity of the modified Gli1 locus. Gli ${ }^{\text {Flox }}$ mice were crossed

\section{Genotyping}

Mice were genotyped by PCR of genomic DNA from tail clips using DreamTaq Green PCR

\section{Genotyping primers}

\begin{tabular}{|c|c|c|l|}
\hline Reaction & $\begin{array}{c}\text { Ta } \\
\left({ }^{\circ} \mathbf{C}\right)\end{array}$ & $\begin{array}{c}\text { Amplicon } \\
(\mathbf{b p})\end{array}$ & Sequences \\
\hline Ai9 wt & 56 & 297 & $\begin{array}{l}\text { F: AAG GGA GCT GCA GTG GAG TA } \\
\text { R: CCG AAA ATC TGT GGG AAG TC }\end{array}$ \\
\hline Ai9 mut & 56 & 196 & $\begin{array}{l}\text { F: GGC ATT AAA GCA GCG TAT CC } \\
\text { R: CTG TTC CTG TAC GGC ATG G }\end{array}$ \\
\hline Egr2 wt/flox & 55 & $\begin{array}{c}150(\mathrm{wt}) \\
250(\text { flox })\end{array}$ & $\begin{array}{l}\text { F: TGG TCG GCT CTT TTT ATT GG } \\
\text { R: AAC ACC CAA TAG CAG CAA CA }\end{array}$ \\
\hline RGli1 wt & 60 & 426 & $\begin{array}{l}\text { F: CGT GAT CTG CAA CTC CAG TC } \\
\text { R: GGA GCG GGA GAA ATG GAT ATG }\end{array}$ \\
\hline RGli1 mut & 60 & 305 & $\begin{array}{l}\text { F: CAG GTG TGT AAC GCT CTG GA } \\
\text { R: ATC ACT ACT TGT CAT CGT CAT CCT T }\end{array}$ \\
\hline Gli2 LacZ wt & 60 & 230 & F: CCT GGG GTC AGA AGA CTG AG \\
\hline
\end{tabular}




\begin{tabular}{|c|c|c|l|}
\hline $\begin{array}{c}\text { Gli2 LacZ } \\
\text { mut }\end{array}$ & 60 & 500 & $\begin{array}{l}\text { F: CCT GGG GTC AGA AGA CTG AG } \\
\text { R: TCT GCC AGT TTG AGG GGA CGA C }\end{array}$ \\
\hline Gli1 LacZ & 62 & 821 & $\begin{array}{l}\text { F: GCA TCG AGC TGG GTA ATA AGC GTT GG } \\
\text { R: GAC ACC AGA CCA ACT GGT AAT GGT AG }\end{array}$ \\
\hline Cre & 62 & 300 & $\begin{array}{l}\text { F: TAA AGA TAT CTC ACG TAC TGA CGG TG } \\
\text { R: TCT CTG ACC AGA GTC ATC CTT AGC }\end{array}$ \\
\hline RCE wt/mut & 62 & $550(\mathrm{wt})$ & $\begin{array}{l}\text { F (com): CCC AAA GTC GCT CTG AGT TGT TAT C } \\
\text { R (wt): GAA GGA GCG GGA GAA ATG GAT ATG } \\
\text { R (mut): CCA GGC GGG CCA TTT ACC GTA AG }\end{array}$ \\
\hline Gli1 wt & 65 & 493 & $\begin{array}{l}\text { F: CCA GTT TCT GAG ATG AGG GTT AGA GGC } \\
\text { R: TTG AAT GGG GAA TAC AGG GCT TAC }\end{array}$ \\
\hline Dhh KO wt & 68 & 442 & $\begin{array}{l}\text { F: GGT CCA GGA AGA GCA GCA C } \\
\text { R: ATC CAC GTA TCG GTC AAA GC }\end{array}$ \\
\hline Dhh KO mut & 68 & 110 & $\begin{array}{l}\text { F: GGT CCA GGA AGA GCA GCA C } \\
\text { R: GGC ATG CTG GGG ATG CGG TG }\end{array}$ \\
\hline Gli1 flox wt & 63 & 185 & $\begin{array}{l}\text { F: GAG ACA AAG GCA ACC AGG GG } \\
\text { R: CTG CAC AGC CTC ACA CAG AC }\end{array}$ \\
\hline Gli1 flox mut & 63 & 391 & $\begin{array}{l}\text { F: GAG ACA AAG GCA ACC AGG GG } \\
\text { R: GGC CAG TGA AAG CTC ACT TCT }\end{array}$ \\
\hline
\end{tabular}

\section{Fate mapping}

Cre-mediated recombination was induced in adult mice by intraperitoneal (IP) injections of 20 
For pulse-labelling, a single injection of $10 \mathrm{mg} / \mathrm{mL}$ EdU (Cayman Chemical) in Phosphateaccording to the manufacturer's instructions.

\section{Tissue processing}

Mice were anesthetized using pentobarbital/phenytoin (Beuthanasia, Merck) and transcardially perfused with PBS, followed by 2\% Paraformaldehyde (PFA) in PBS. Sciatic nerves were isolated, pinned to Sylgard 184 (Dow Chemical)-coated plates, and postfixed for $2 \mathrm{hr}$ at $4^{\circ} \mathrm{C}$ on a rocker. Nerves were cryoprotected in 15\% sucrose (ThermoFisher) in PBS overnight, followed by 30\% sucrose, and a 1:1 mixture of OCT (Tissue-Tek) to 30\% sucrose. Finally, nerves were embedded in 2:1 mixture of OCT to $30 \%$ sucrose, flash frozen on liquid $\mathrm{N}_{2}$, and sectioned on a Leica CM $3050 \mathrm{~S}$ cryostat at $12 \mu \mathrm{m}$ in both longitudinal and cross-sectional planes. Sections were collected on Superfrost Plus slides (ThermoFisher) and dried on a slide warmer at $50^{\circ} \mathrm{C}$ overnight before storage at $-80^{\circ} \mathrm{C}$ until use.

\section{Immunofluorescence}

210 Slides were brought to room temperature and incubated in blocking solution containing 1\% Bovine

211 Serum Albumin (BSA, Sigma), 0.25\% Triton X-100 (Sigma), and 10\% Normal goat serum (Vector

212 Labs) in PBS for $1 \mathrm{hr}$ at room temperature. When goat primary antibodies were included, 10\%

213 Normal donkey serum (Jackson Immuno) was used instead. For staining of myelin proteins, slides

214 were permeabilized in Acetone for $20 \mathrm{~min}$ at $-20^{\circ} \mathrm{C}$ prior to blocking. After blocking, slides were

215 incubated with primary antibodies diluted in blocking solution overnight at $4^{\circ} \mathrm{C}$. Slides were 
washed in $0.1 \%$ Triton X-100 in PBS (PBS-T) for $3 \times 5 \mathrm{~min}$, then incubated with appropriate goat

or donkey species-specific secondary antibodies (Jackson Immuno) diluted 1:1000 in blocking

218 solution for $2 \mathrm{hr}$ at room temperature. Slides were washed again in PBS-T and mounted with

219 Fluoromount-G (Southern Biotech). To label nuclei, some slides were also incubated in Hoechst

22033258 (ThermoFisher) diluted 1:5000 in PBS for $5 \mathrm{~min}$ at room temperature prior to mounting.

221 Fluorescent images were obtained with an LSM 800 Scanning Confocal Microscope (Carl Zeiss)

222 using ZEN Blue software (Carl Zeiss). Images were processed using Fiji (NIH) and Photoshop

223 (Adobe). Quantifications were performed on blinded images using counting and tracing tools in

224 Fiji and Photoshop.

225

226

Primary antibodies

\begin{tabular}{|c|c|c|c|}
\hline Target & Species (clone) & Source (cat\#) & Dilution \\
\hline$\beta \mathrm{Gal}$ & ck & Abcam (ab9361) & 1 to 2000 \\
\hline CD31 & rt (390) & Biolegend (102416) & 1 to 500 \\
\hline CD31 & rt (MEC 13.3) & Biolegend (102515) & 1 to 500 \\
\hline CD34 & rb (EP373Y) & Abcam (ab198395) & 1 to 500 \\
\hline Collagen-1 & $\mathrm{rb}$ & Abcam (ab21286) & 1 to 200 \\
\hline $\mathrm{F} 4 / 80$ & rt (A3-1) & Biorad (MCA497GA) & 1 to 500 \\
\hline Fibronectin & $\mathrm{rb}$ & Chemicon (AB2033) & 1 to 500 \\
\hline GFP & $\mathrm{rb}$ & Thermo (A11122) & 1 to 1000 \\
\hline GFP & $\mathrm{ck}$ & Thermo (A10262) & 1 to 500 \\
\hline Glut-1 & rb (EPR3915) & Abcam (ab115730) & 1 to 500 \\
\hline Ki67 & $\mathrm{rb}$ & Millipore (AB9260) & 1 to 400 \\
\hline L1CAM & rt (324) & Millipore (MAB5272) & 1 to 100 \\
\hline MBP & ms IgG2b (SMI99) & Biolegend (808401) & 1 to 400 \\
\hline MBP & $\mathrm{ck}$ & Millipore (AB9348) & 1 to 100 \\
\hline NG2 (CSPG4) & $\mathrm{rb}$ & Millipore (AB5320) & 1 to 500 \\
\hline P0 (MPZ) & ck & Millipore (AB9352) & 1 to 50 \\
\hline PDGFRa (CD140a) & rt IgG2a (APA5) & $\mathrm{BD}(558774)$ & 1 to 200 \\
\hline PDGFRa (CD140a) & $\mathrm{gt}$ & R\&D (AF1062-SP) & 1 to 500 \\
\hline RFP & ms IgG1 (RF5R) & Invitrogen (MA5-15257) & 1 to 500 \\
\hline RFP & $\mathrm{rb}$ & Rockland (600-401-379) & 1 to 1000 \\
\hline
\end{tabular}




\begin{tabular}{|l|l|l|l|}
\hline RFP & rt (5F8) & Chromotek (5f8) & 1 to 1000 \\
\hline S100 $\beta$ & rb & Dako (Z0311) & 1 to 500 \\
\hline SMA & ms IgG2a (1A4) & Abcam (ab7817) & 1 to 1000 \\
\hline Sox10 & gt & R\&D Systems (AF2864) & 1 to 100 \\
\hline ZO-1 & ms IgG1 (1A12) & Thermo (33-9100) & 1 to 500 \\
\hline
\end{tabular}

\section{Masson's Trichrome Staining}

Sciatic nerves were fixed as above, but instead of embedding in OCT, nerves were

\section{Barrier Permeability Studies}

To test the integrity of the BNB, a solution of 1\% Evans Blue (Sigma), 5\% BSA (Sigma) in 
in OCT, and flash frozen in liquid $\mathrm{N}_{2}$. Nerve cross sections were cut at $12 \mu \mathrm{m}$ on a Leica CM 3050S cryostat and collected on Superfrost Plus slides. EBA fluorescence was visualized immediately without coverslipping using a Zeiss AxioImager A2 (filter cube: Ex:542-582 nm, Em: 604-644nm).

\section{Transmission Electron Microscopy}

Mice were anesthetized and underwent trans-cardiac perfusion with $0.1 \mathrm{M}$ sodium

255 Cacodylate (EMS) followed by Karnovsky’s fixative (4\% PFA, 2\% glutaraldehyde, 0.1 M sodium cacodylate, $\mathrm{pH}$ 7.4). Nerves were removed and postfixed in Karnovsky's fixative for at least $72 \mathrm{hr}$ at $4{ }^{\circ} \mathrm{C}$ with gentle agitation. Samples were then washed in $0.1 \mathrm{M}$ sodium cacodylate, and then post-fixed for $1 \mathrm{hr}$ in $1 \%$ osmium tetroxide (EMS) in $0.1 \mathrm{M}$ sodium cacodylate. Nerves were then dehydrated in increasing concentrations of ethanol followed by propylene oxide (PO, EMS). embedded in $100 \%$ Embed 812 and baked at $55^{\circ} \mathrm{C}$ for $72 \mathrm{hr}$.

Tissue blocks were sectioned on a Leica UC6 ultramicrotome at a thickness of $1 \mu \mathrm{m}$ for semithin and $90 \mathrm{~nm}$ for ultrathin sectioning. Semithin sections were placed on glass slides and stained with $1 \%$ Toluidine blue, $2 \%$ Borate in water for 1-2 mins. Ultrathin sections were placed 
271 Gemini 300 SEM with Gatan 3View in STEM mode.

\section{Calculation of nerve area, axon diameters, and g-ratios}

Cross-sectional area of nerves was calculated from Toluidine blue-stained semithin nerve upon request.

For 3View SEM tissue processing, the standard transmission electron microscopy protocol and mounted on slot grids. For STEM imaging, grids were loaded onto the Zeiss grid holder.

SBF SEM imaging, the sample block was mounted on an aluminum specimen pin (Gatan, 
DESK V sputter coater, Denton Bacuum, LLC., NJ, USA). Serial block face imaging was imaged with gas injection setting at 40\% (2.9E-03mBar) with Focus Charge Compensation to reduce the charge, and images were recorded after each round of section from the block face using the SEM beam at $1.2 \mathrm{keV}$ with a dwell time of $1.2 \mu \mathrm{s} /$ pixel. Each frame is $60 \mathrm{x} 75$ um with pixel size of $3.5 \mathrm{~nm}$. Data acquisition occurred in an automated way using Gatan Digital Micrograph (version 3.31) software. A stack of 150 slices was aligned, assembled using ImageJ, with a volume of $60 \times 75 \times 15 \mu \mathrm{m}^{3}$ dimensions was obtained from the tissue block. Segmentation and video were generated by Dragonfly $4.1(\mathrm{ORS})$.

\section{RNA Isolation and Reverse Transcription}

Total RNA was isolated from mouse sciatic nerves using Trizol Reagent (Invitrogen). Flash frozen nerves were pulverized in $1.5 \mathrm{~mL}$ Eppendorf tubes over liquid nitrogen using a plastictipped electric homogenizer. $1 \mathrm{~mL}$ of Trizol was added to each nerve samples and allowed to thaw on ice. Samples were centrifuged at $12,000 \mathrm{G}$ for $12 \mathrm{~min}$ at $4^{\circ} \mathrm{C}$ to pellet lipids and cellular debris. protocol per manufacturer's instructions with the addition of $15 \mu \mathrm{g}$ of Glycoblue coprecipitant 


\section{Quantitative PCR}

Target gene expression was assessed using a BioRad CFX96 thermal cycler in a total reaction volume of $15 \mu \mathrm{L}$ using PowerUP SYBR Green master mix (ThermoFisher) and $1 \mu \mathrm{L}$ of cDNA per reaction. Standard qPCR settings were used: $95^{\circ} \mathrm{C}$ for $10 \mathrm{~min}$ followed by 40 cycles of $95^{\circ} \mathrm{C}$ for $15 \mathrm{~s}$ then $60^{\circ} \mathrm{C}$ for $30 \mathrm{~s}$, followed by melt curve analysis. Ct values for each target gene were internally normalized to the average of at least 2 housekeeping genes (Gln, Hprt1, and CNP1) in each sample and analyzed using the comparative Ct method (Livak and Schmittgen 2001). is arbitrarily normalized to 1.0 .

For all experiments, primers were designed online using Primer-BLAST (NCBI) and were

(genome.ucsc.edu).

\begin{tabular}{|l|l|c|l|}
\hline Target & Refseq (NCBI) & $\begin{array}{c}\text { Amplicon } \\
(\mathbf{b p})\end{array}$ & Primer Sequences \\
\hline CNP1 & NM_001146318.1 & 147 & $\begin{array}{l}\text { F: GAA GAA TAC GCC CAG CAG GA } \\
\text { R: CAG ATC ACT GGG CCA CAA CT }\end{array}$ \\
\hline Col1A1 & NM_007742.4 & 141 & $\begin{array}{l}\text { F: GAC GCA TGG CCA AGA AGA CA } \\
\text { R: CAT TGC ACG TCA TCG CAC AC }\end{array}$ \\
\hline Col1A2 & NM_007743.3 & 139 & $\begin{array}{l}\text { F: GGG TGT TCA AGG TGG CAA AG } \\
\text { R: ACC AGG GAG ACC GAA TTC AC }\end{array}$ \\
\hline Col3A1 & NM_009930.2 & 110 & $\begin{array}{l}\text { F: TTG TGC AAA GTG GAA CCT GG } \\
\text { R: ATA GGA CTG ACC AAG GTG GC }\end{array}$ \\
\hline Dhh & NM_007857.5 & 141 & $\begin{array}{l}\text { F: CAG ACC GCC TGA TGA CAG AG } \\
\text { R: AGT GGA GTG AAT CCT GTG CG }\end{array}$ \\
\hline Egr2 & NM_001347458.1 & 155 & $\begin{array}{l}\text { F: GCC CCT TTG ACC AGA TGA AC } \\
\text { R: GGA GAA TTT GCC CAT GTA AGT G }\end{array}$ \\
\hline
\end{tabular}




\begin{tabular}{|l|l|c|l|}
\hline Gli1 & NM_010296.2 & 136 & $\begin{array}{l}\text { F: GGA ATT CGT GTG CCA TTG GG } \\
\text { R: GGA CTT CCG ACA GCC TTC AA }\end{array}$ \\
\hline Gln & NM_177350.5 & 139 & $\begin{array}{l}\text { F: AGC AGA AGA TCC AAA GGC CC } \\
\text { R: CTG TTT GTG GTG AAT GGC GT }\end{array}$ \\
\hline Hprt1 & NM_013556.2 & 131 & $\begin{array}{l}\text { F: GTT AAG CAG TAC AGC CCC AAA } \\
\text { R: AGG GCA TAT CCA ACA ACA AAC TT }\end{array}$ \\
\hline Shh & NM_009170.3 & 135 & $\begin{array}{l}\text { F: GGA AGA TCA CAA GAA ACT CCG AAC } \\
\text { R: GAT GGC CAA GGC ATT TAA CTT GT }\end{array}$ \\
\hline
\end{tabular}

\section{Sciatic Nerve Explant Cultures}

Gli1 het and null mice were euthanized by $\mathrm{CO}_{2}$ narcosis and sciatic nerves were rapidly dissected and placed in cold L-15 media (Sigma). Nerve cultures from each biological replicate were maintained separately. Each nerve was sliced into $\sim 1 \mathrm{~mm}$ segments using a sterile razor blade. segments were transferred to the center of a well in a 6-well tissue culture plate and covered with a minimal $(<200 \mu \mathrm{L})$ amount of media. A glass coverslip was gently placed on top of the explant to ensure adherence and the well was flooded with $1 \mathrm{~mL}$ of EF media consisting of DMEM (Thermo) containing 20\% FBS (Gemini). After 5 days, nerve segments and overlying coverslips were removed with sterile forceps and cells that had migrated out from explants were dissociated by addition of $500 \mu \mathrm{L}$ Trypsin-EDTA (Sigma) to each well. Cells were passaged at a density of $\sim 5,000$ cells $/ \mathrm{cm}^{2}$ every 7 days for 2 passages to remove any contaminating SCs. Finally, EF density of $\sim 5,000$ cells $/ \mathrm{cm}^{2}$ in either regular EF or GANT61-containing media in 6-cm plates. 
and RNA was isolated as above for sciatic nerves with the omission of the initial centrifugation were passaged in EF media at either 2,000 or 10,000 cells $/ \mathrm{cm}^{2}$ on glass coverslips for $48 \mathrm{hr}$, fixed in $2 \%$ PFA for 10 minutes, and processed for immunofluorescence as above.

\section{Experimental Design and Statistical Analysis}

Mice of both sexes were used in equal ratios whenever possible. All mutants were prepared for each genotype and all reactions were run in technical triplicate. For all cell counts, proliferation assays, collagen fibril quantification, perineurial thickness, and axon/myelin morphometry, at least 10 individual fields were averaged from each of 3 biological replicates per genotype.

For pairwise comparisons, 2-tailed unpaired t-tests were used with Welch's correction to account for unequal standard deviations between samples. When multiple comparisons of means were required, Brown-Forsythe and Welch ANOVA tests were used with Dunnet's T3 multiple comparisons test and a family-wise significance level of 0.05 . For assessment of categorical data

(such as binned axon diameters), Fisher's exact test was used to compare numbers of samples failing in each bin with the total number of observations for that sample. For Remak bundle analysis, the number of observations was not sufficient to perform statistical testing by Fisher's test. All statistical operations and generation of graphs were performed in Prism 8 (GraphPad). 


\section{$371 \quad$ RESULTS}

\section{Gli1 is expressed in multiple PNS cell types}

373 To identify the full roster of Gli1-expressing cells in the PNS, we fate mapped these cells

374 by crossing Gli $1^{\text {CreERT2/+ }}$ mice (Ahn and Joyner, 2004) with the Rosa26flox-stop-flox-tdTomato (Ai9)

375 reporter (Madisen et al., 2010) to generate $\mathrm{Glil}^{\mathrm{CE/+}} ; \mathrm{Ai9}$ mice, referred to hereafter as Gli1 hets.

376 Tamoxifen administration in these mice results in permanent labeling of all Gli1-expressing cells

377 and their progeny with cytoplasmic tdTomato (tdT). Fate mapped sciatic nerves from Gli1 hets

378 showed robust tdT labeling of both perineurium (Figure 1B, C, arrows) and cells present 379 throughout the endoneurium (Figure 1B, C, arrowheads).

We found that virtually all fate mapped cells express PDGFR $\alpha$, recently reported to be a

381 broad marker of both PNG and EFs (Richard et al., 2014; Carr et al., 2019) (Figure 1D).

382 Endoneurial fate mapped cells also co-expressed NG2, a known EF marker (Richard et al., 2014)

383 (Figure 1E). Labeling of all cell layers in the perineurium was demonstrated by immuno-EM for a

384 reporter allele driven by Gli1 ${ }^{C E}$ (Figure 1F). Fate mapped perineurial cells also expressed a lattice

385 of ZO-1, a component of the tight junctions that forms between adjacent layers of PNG

386 (Tserentsoodol et al., 1999) (Figure 1G). Finally, we stained nerves for Glut-1/SLC2A1 and CD34,

387 recently confirmed to be selectively enriched in PNG and EFs, respectively in a single cell RNAseq

388 analysis (Gerber et al., 2021). Accordingly, Glut-1 labels fate mapped PNG, but not EFs (Figure

$3891 \mathrm{H}$ ) and CD34 labels fate mapped EFs, but not PNG (Figure 1I, J).

390

There is an additional population of endoneurial Gli1-expressing cells tightly associated

391 with CD31-positive endothelial cells (ECs) that co-expressed aSMA (Figure 1K) as well as

392 PDGFR $\beta$ (data not shown). These perivascular cells are likely Glil-positive pericytes that

393 surround endoneurial capillaries or postcapillary venules (Bell and Weddell, 1984b). All other 
394 PNS cell types, including ECs, macrophages, and both mSCs and Remak SCs were Gli1-negative

395 (data not shown). In summary, PNG, EF, and pericytes in peripheral nerves are Glil-expressing 396 cells based on fate mapping and can be distinguished by cell-type-specific markers.

Dhh expression is largely confined to mSCs (Parmantier et al., 1999). In agreement, transcription of the Dhh gene in SCs is upregulated by the transcription factor Egr2 (Jang et al., 401 2006), which is required for terminal differentiation of promyelinating SCs into mSCs (Murphy et al., 1996). To determine if Gli1 expression in peripheral nerves, like Dhh, depends on myelination, we generated SC-specific Egr2 conditional knockouts (Egr2 cKO) by crossing MPZ-Cre transgenic mice (Feltri et al., 1999) to Egr2floxflox mice (Du et al., 2014). These mice were then crossed to Gli1 ${ }^{n L a c Z}$ mice, which express nuclear-localized $\beta$-Galactosidase ( $\beta$ Gal) from the endogenous Gli1 locus and therefore provide a readout for active Gli1 expression (Bai et al., 2002). We generated both $G l i 1^{\mathrm{LacZ/+}} ; E g r 2^{\text {flox/++}}$ (het controls) and Gli ${ }^{\text {nLacZ/+}} ;$ MPZ-Cre; Egr flox/flox $(\mathrm{cKO})$

408 reporter mice. Electron microscopy (EM) analysis showed SCs in the het controls myelinated normally (Figure 2B) whereas SCs in the cKOs were arrested at the promyelinating stage and did

410 not form any myelin (Figure 2D), as expected (Topilko et al., 1994). PDGFR $\alpha$ was used to identify

411 PNG and EFs.

413 the Egr2 cKOs (Figure 2C). The density of EFs appeared to be increased with marked process

414 extension compared to controls, but there was not frank MF formation based on staining or EMs

415 (Figures 2C, 2D arrowhead). qPCR of the Egr2 cKOs demonstrated a $\sim 50 \%$ reduction in Dhh and 416 a comparable reduction of Gli1 transcripts (Figure 2E). Together, these results indicate that SC 
417 Egr2 expression, which is required for myelination, drives Dhh expression in mSCs and Gli1 418 expression and phenotypic changes in prospective target cells during postnatal PNS development.

\section{Gli1 expression in EFs is independent of Dhh}

Given the coordinate regulation of Dhh and Gli1 in the Egr2 cKOs, we considered Dhh a

422 potential candidate to drive expression of Gli1 in the PNS. Dhh is also the only member of the Hh

423 family normally expressed in the postnatal PNS (Gerber et al., 2021). In the canonical Hh pathway,

424 Gli1 expression is activated by Gli2A function (Wilson and Chuang, 2010). We therefore first 425 assessed Gli2 expression by crossing $\mathrm{Glil}^{\mathrm{CE/+}}$; $\mathrm{Ai} 9$ mice to $\mathrm{Gli}^{\text {nLacZ/+}}$ mice (Bai and Joyner, 2001).

426 This revealed that both endoneurial and perineurial Gli1-positive cells co-expressed Gli2

427 (Extended data Figure 1), consistent with canonical Hh signaling as a driver of Glil expression in 428 these cells.

429 To examine directly whether Gli1 is downstream of Dhh, we crossed Gli ${ }^{\text {LacZ/+ }}{ }^{\text {reporter }}$ 430 mice to $D h h^{-/}$nulls (Bitgood et al., 1996). In the Dhh nulls, as previously reported (Parmantier et 431 al., 1999), the perineurium is largely deficient (Figure 2F, I, arrows) and there is robust MF 432 formation (arrowheads). Both effects were already evident at P5 based on staining of Dhh null

433 nerves for PDGFR $\alpha$ (Figure 2F, I). Elongated cellular processes were observed throughout the 434 endoneurium by EM in P5 Dhh nulls (Figure 2G, arrowheads), with mature MF structures 435 consisting of several cell layers visible by P25 (Figure 2J, arrowheads).

$4372 \mathrm{~F}$ ) and P25 (Figure 2I) based on $\beta$ Gal staining. Likewise, by qPCR Glil mRNA was expressed 438 in the P5 Dhh nulls, albeit at reduced levels i.e., 56\% of controls (Figure 2H). Gli1 levels were 439 normal or even increased in the P25 Dhh nulls compared to controls despite the absence of Dhh 
440 (Figure 2K). The amount of Gli1 expression is particularly striking as there is no contribution from

441 Gli1-positive perineurial cells. All $\beta$ Gal-positive cells in the Dhh nulls expressed PDGFR $\alpha$,

442 indicating that the persistent Glil expression remained confined to EFs and was not induced in 443 other cell types, e.g., SCs.

444 Expression of Gli1 in the Dhh KOs suggests that either other Hh members are upregulated 445 in the Dhh nulls or there is significant non-canonical i.e., Hh-independent induction of Gli1 in EFs.

446 By qPCR, Shh and Ihh transcripts were not detected in P5 Dhh KOs, in Gli1 hets or nulls, or in

447 Egr2 cKOs (data not shown). There may be a small amount of Shh transcripts in the P25 Dhh KOs

448 based on variable detection of an amplicon in PCR cycles 33-38. This varied between biological

449 replicates of the same genotype and even when detected, was much lower than the levels of Dhh 450 in P25 controls, which amplified in cycles 22-23. These results indicate that expression of Gli1, at

451 least in EFs, is largely Hh-independent.

452

453 Gli1 controls endoneurial but not perineurial development

454 To test the function of Gli1 in the PNS, we generated Gli1 knockout mice by crossing 455 Gli1 ${ }^{C E /+} ; A i 9$ mice with $G l i 1^{\text {LacZ/+ }}$ mice. The resulting Gli1 nulls $\left(G l i 1^{\text {CE/LacZ }}\right.$;Ai9) were compared 456 to Gli1 hets $\left(G l i 1^{C E /+} ; A i 9\right)$; a single copy of Gli ${ }^{C E}$ present in both the hets and nulls was used for 457 fate mapping. As previously reported (Park et al., 2000), Glil nulls were born at predicted 458 Mendelian ratios and displayed no overt phenotype. qPCR of sciatic nerves confirmed that Gli1 459 transcript levels in nulls were reduced to less than 5\% of the Gli1 hets (data not shown). As Gli1 460 hets have no evident phenotype and their nerves appeared identical to wild-type nerves by fate 461 mapping and EM (Figure 3A and inset), they were used as controls in all subsequent studies. 
Nerves from the Gli1 nulls were strikingly organized into MFs, which were formed by thin,

463 closely-associated Gli1 fate mapped processes (Figure 3B and inset). These structures appeared

464 very similar to Dhh null nerves. Both the perineurium and MFs remained PDGFR $\alpha$-positive in the

465 Gli1 nulls (Figure 3C). In contrast to the endoneurium, the epineurium and perineurium in the Gli1

466 nulls appeared normal in appearance and similar to controls (Figure 3D, E). By EM, the

467 perineurium of Gli1 nulls contained similar numbers of layers as the Gli1 hets i.e., $5.42 \pm 0.46$ vs.

$4686.17 \pm 0.36$, respectively. This contrasts with the Dhh null nerves, which have a minimal

469 epineurium and perineurium (Figure 3F) and, as a result a defective diffusion barrier (Parmantier

470 et al., 1999).

471 To test if the perineurial diffusion barrier was indeed intact in the Gli1 nulls as suggested

472 by its morphology, we injected Evans Blue Albumin (EBA), a $69 \mathrm{kD}$ fluorescent protein tracer

473 (Wolman et al., 1981), into the local tissue compartment around the nerve. This dye failed to 474 penetrate the perineurium of either the Gli1 hets or nulls (Figure 3G, H, arrows). A very small

475 amount of EBA did track along MF boundaries in the Gli1 nulls, entering at points where MFs

476 anastomose with the overlying perineurium, but did not enter the endoneurial space (Figure $3 \mathrm{H}$,

477 inset). A barrier in the MFs is consistent with the presence of continuous ZO-1 expression between

478 MF-forming cells in the Gli1 nulls (Figure 3I, arrowhead), reflecting the presence of tight

479 junctions. Finally, whereas in Dhh nulls, degenerating/regenerating fibers were noted in aged 480 animals (Sharghi-Namini et al., 2006), none were observed by EM in Gli1 nulls as old as 18 months 481 (data not shown). Thus, proper development of the epi/perineurium and the perineurial barrier 482 requires Dhh but is independent of Glil expression. 
A key question is what cell gives rise to MFs. As MFs share structural features with PNG, including forming tight junctions and a basal lamina, PNG precursors that invade the endoneurial

487 space have been proposed as a source (Parmantier et al., 1999). Alternatively, EFs within the

488 endoneurial compartment may differentiate and acquire properties of the PNG to form MFs. This

489 latter possibility is consistent with the finding that fibroblasts added to myelinating SC/neuron

490 cocultures form perineurial-like structures (Bunge et al., 1989).

491

To examine the origins of MFs further, we determined when the EF and PNG cell

492 populations arise relative to MF formation. To this end, we carried out in utero fate mapping of

493 Gli1 het and null mice by oral gavage of pregnant females at embryonic day 13 (E13) and

494 examined nerves at postnatal day 30 (P30). In hets, this resulted in labeling of both PNG and EFs

495 but not SCs (Figure 4A). Similarly, in Gli1 nulls the MF-forming cells and PNG but not SCs are

496 labeled (Figure 4B). Thus, Gli1-positive precursors to EF and PNG are present early in

497 development and either may potentially contribute to the formation of MFs.

We next characterized when MFs form by analyzing sciatic nerves at different postnatal

499 ages by EM including at P1, P10 and in adults (Figure 4C-H). P1 nerves in both Gli1 hets and nulls

500 contain many EFs, evident as large, flattened cells in the spaces in between developing axon

501 bundles ensheathed by SCs (Figure 4C, D; highlighted in red in insets). At P10 in Gli1 het nerves,

502 these cells begin to remodel, retracting their processes and adopting a more fusiform morphology

503 (Figure 4E). This remodeling continues into adulthood - mature EFs have short processes and lack

504 a basal lamina (4G, white arrow in inset) compared to SCs (4G, yellow arrow in inset); this is

505 consistent with a previous characterization (Richard et al., 2014). In contrast, endoneurial cells in

506 the Gli1 nulls do not retract their processes but rather progressively extend very thin processes

507 around multiple SC/axon units (both mSCs and Remak SCs), evident at P5 (data not shown) and 
508 largely complete by P10 (Figure 4F). Their appearance at P10 strongly resembles MFs in adult

509 Gli1 nulls (Figure 4H), including production of a robust basal lamina (see 4H, white arrow in

510 inset). These observations support the notion that MFs arise in a Gli1-dependent fashion, at least

511 in part via remodeling of immature EFs between P1-P10.

\section{EF but not PNG proliferation is increased in Gli1 nulls}

$514 \quad$ Formation of MFs is associated with an increase in the numbers of its constituent cells. We

515 therefore counted Gli1-positive EF and PNG, indicated by positive $\beta$ Gal immunostaining in

516 Gli1 $^{\mathrm{LacZ} /+}$ hets and Gli1 ${ }^{\mathrm{CE} / \mathrm{LacZ}}$ nulls; Sox 10 served as a marker of SCs (Figure 5A, B). There were

517 roughly twice as many $\beta$ Gal-positive, Sox10-negative cells (i.e., EF/PNG) in Gli1 nulls vs hets

518 starting at P5 - an increase that persisted into adulthood (Figure 5C). To determine if this increase

519 resulted from increased cell proliferation in the Glil nulls, we pulse labeled with EdU at various

520 developmental ages and counted EdU-positive cells in the endoneurium and perineurium. This

521 revealed an increase in EdU incorporation in $\beta$ Gal-positive, Sox10-negative cells in the Gli1 nulls

522 from $\mathrm{P} 1$ to $\mathrm{P} 10$. The increase in proliferation was exclusively in the endoneurium, not the

523 perineurium (Figure 5D) supporting the notion that MF formation originates from the proliferation

524 and reorganization of EFs. In further support, there were fewer "free" EFs (i.e., single cells within

525 the endoneurium) in adult Gli1 null nerves, suggesting their disappearance from the endoneurium

526 reflects their accumulation into MFs (Figure 5E-G). By P15 only a few EdU+ cells were detected

527 in either genotype and none were observed in adults (data not shown) consistent with MF

528 formation being largely established by P10 (see Figure 4) and that once formed, these structures

529 are stable. 
To confirm that Gli1 expression regulates EF proliferation in a cell-autonomous fashion,

531 we characterized fate mapped cells derived from sciatic nerve explants of Gli1 hets and nulls.

532 Spindle-shaped tdT-positive cells rapidly migrated out of the ends of het and null sciatic nerve

533 segments explanted into culture. These cells were passaged in high-serum media without

534 additional growth factors, conditions which enhance survival of EF/PNG and eliminates SC

535 contamination (Ochoa and Spinel, 2010). In such cultures, the tdT cells gradually adopted a

536 flattened morphology, and expressed fibronectin and ZO-1, further establishing them as EFs and/or

537 PNG (Peltonen et al., 1987) (data not shown). We then counted the number of tdT-positive cells

$53848 \mathrm{hr}$ after plating and also stained for Ki67 to mark mitotic cells (Figure 6A-C). We found a

539 significant increase in cell density (Figure 6D) and proliferation (Figure 6E) in knockout cultures

540 compared to controls. Further, addition of $5 \mu \mathrm{M}$ GANT-61, a pharmacological inhibitor of Gli1

541 and Gli2 activity (Lauth et al., 2007), increased cell density (Figure 6D) and cell proliferation

542 (Figure 6E) in control cultures to the same levels as the Gli1 nulls. The efficacy of GANT-61

543 treatment was corroborated by the significant reduction in Gli1 transcript levels (Figure 6F); there

544 was also a $\sim 25 \%$ reduction in Gli2 transcript levels, which did not quite reach significance (data

545 not shown).

546

\section{Cell marker analysis implicates EFs in MF assembly}

548 To address further which cells give rise to MFs, we stained perinatal and adult sciatic

549 nerves of Gli1 (Figure 7B, E, H, K) and Dhh (Figure 7C, F, I, L) nulls for CD34 and Glut-1, 550 markers enriched in EFs and PNG in wild type nerves, respectively (see Figure 1H-J). Nerves were

551 also stained for PDGFR $\alpha$ to demarcate cells corresponding to the Gli1-fate mapped population

552 (see Figures 1D, 3C). This analysis showed that MFs forming in early postnatal (P5) Dhh and Gli1 
553 nulls (panels A-F) were almost exclusively comprised of CD34-positive, Glut-1-negative cells, 554 providing further evidence that forming MFs arise from EFs and not PNG.

555 In contrast, in the adult Dhh and Gli1 nulls (panels G-L), cells that comprise MFs express

556 both CD34 and Glut-1. This may reflect that these MFs contain a mixture of cells that express

557 either CD34 or Glut-1 or, alternatively that a single population of CD34-positive cells upregulates

558 Glut-1 as MFs mature. We were unable to double stain nerves to determine if Glut-1 and CD34

559 are co-expressed or are in separate cell populations as, based on our testing, the most reliable

560 commercially-available antibodies to these markers are both raised in rabbit. However, the

561 widespread expression of both markers in the MFs of both Glil and Dhh nulls (Figure 7) and the

562 relatively uniform cytoarchitecture of these structures by EM (Figure 4H) suggests adult MFs are

563 comprised of a single population of cells that co-express both markers.

564 We next examined if expression of these markers, particularly Glut-1, is upregulated in

565 adult MFs potentially as the result of increased cell density and cell contact characteristic of these

566 adult structures. We therefore analyzed cultures of fate mapped cells from Gli1 het and null sciatic

567 nerves grown at low and high cell density (Extended data Figure 2). We found that CD34

568 expression is higher when these cells are grown at lower density, whereas Glut-1 expression,

569 visible along the membranes of cells in direct contact, is only expressed when cells are grown at

570 high density. The staining data, taken together with the EM and proliferation studies described

571 above, support EFs as the likely cell of origin for MFs in both Glil and Dhh nulls. They also

572 suggest these structures eventually acquire perineurial features including Glut-1 expression, 573 possibly as a result of increased cell-cell contact.

\section{Gli1 regulates endoneurial architecture}


We next examined whether there were other changes in nerve architecture in the Gli1 nulls,

577 in addition to MFs, focusing on the vasculature, the ECM, and axon-SC units. 3D reconstruction

578 of nerves from Gli1 nulls by serial block-face scanning EM (SBF-EM) showed that most

579 endoneurial blood vessels are embedded within MFs (Extended data video 1). Staining cross

580 sections of nerves for CD31 to label ECs confirmed that Glil-positive cells were closely associated

581 with blood vessels in both Gli1 hets and nulls (Figure 8A, B, insets). We also saw a significant

582 increase in the overall number of blood vessels in Gli1 nulls compared to het controls (Figure 8C).

583 The increased blood vessel density and the close spatial relationship of Gli1-positive cells with

584 blood vessels was evident at all timepoints starting at P1 (Figure 8D, E), suggesting an increase in

585 developmental vascularization rather than neovascularization occurring in adults. The BNB was

586 grossly intact as intravenously-injected EBA was confined to blood vessels and the narrow space

587 within fascicle walls, never entering the interior of the fascicles in Gli1 nulls (Figure 8F, G). In

588 both genotypes, EBA leaked out from epineurial capillaries, which are known to be fenestrated

589 and lack tight junctions (Olsson, 1990). We also monitored macrophage numbers by crossing Gli1

590 hets and nulls to CX3CR1 ${ }^{\mathrm{EGFP} /+}$ reporter mice (Jung et al., 2000) and saw no significant difference

591 in macrophage numbers between genotypes (Figure 8H-J). Together, this data supports a role of

592 Gli1 expression in endoneurial cells non-autonomously regulating development of the nerve

593 vasculature, but not BNB integrity.

594 We next compared the ultrastructure of Gli1 het and null peripheral nerves by EM (Figures

$5959,10)$ and by staining of semi-thin $(1 \mu \mathrm{m})$ sections with Toluidine Blue (data not shown). A striking

596 finding is a strong reduction in fibrillar collagen in the ECM of the Gli1 null endoneurium (Figure

597 9A-C). In agreement, staining for collagen with either Masson's Trichrome (Figure 9D, E) or with

598 an antibody against Collagen-1 (Figure 9F, G) was substantially reduced in the Gli1 nulls. EFs 
599 largely generate non-basal lamina-associated, fibrillar collagens via their expression of the salient 600 collagen transcripts (Col1a1, Colla2, Col3a1) and high levels of prolyl-4-hydroxylase (Richard et

601 al., 2014; Carr et al., 2019), an enzyme critical for collagen synthesis. We confirmed there is a 602 significant decrease in Col1A1, 1A2, and 3A1 transcripts in Gli1 null nerves by qPCR (Figure 603 9H). Thus, a decrease in EF collagen synthesis accompanies their phenotypic shift towards MF 604 formation.

606 Gli1 regulates axon-Schwann cell units non-autonomously

Along with a reduction in the ECM, there were significant changes in axon-SC units. These

608 included a significant decrease in the packing density of axon-SC units in Glil null nerves 609 compared to hets as evident by EM (Figure 10A-C). This decrease in density in the nulls reflects 610 increased spacing, not axonal loss as the numbers of axons in the het and null nerves were 611 equivalent (Figure 10D). In agreement, the nerves in the Gli1 nulls were nearly 50\% larger in their 612 cross-sectional area (data not shown).

613 In addition to altered density, there were also modest changes in the ultrastructure of axon-

614 SC units. Myelin sheaths were, on average, slightly thicker in the Gli1 nulls indicated by a decrease

615 in the g-ratios for small- and medium-diameter myelinated axons in the Gli1 nulls compared to 616 hets (Figure 10E, F). There was also a modest (leftward) shift in the distribution of axon diameters 617 in Gli1 nulls with increased numbers of smaller and fewer numbers of large-diameter axons 618 (Figure 8G). Finally, there is a bias towards lower SC:axon ratios (i.e., more 1:1 and 1:2 vs. fewer $6191: 11+$ ) in Remak fibers of Gli1 nulls than hets (Figure 10H-J). Given that neither neurons nor SCs 620 express Gli1, these latter findings suggest a non-autonomous role of Gli1, likely via EFs, in 621 regulating the precise ultrastructure of axon-SC units. 


\section{Gli1 maintains the endoneurial organization of adult peripheral nerves}

These studies indicate that Glil regulates the organization of the endoneurium during

625 development. An important question is whether Gli1 is also required to maintain this organization

626 in adult nerves. To address this question, we first generated a floxed allele of Gli1 as shown

627 schematically in Figure 11A. The fidelity of the insertion of loxP sites was corroborated by

628 sequencing. Mice with the floxed Gli1 allele were crossed to the Gli ${ }^{C E /+}$ driver and the Ai9

629 reporter to generate mice with $G l i 1^{C E / F l} ; A i 9$ and $G l i 1^{C E /+} ; A i 9$ genotypes, enabling Gli1 fate

630 mapping of inducible KOs (iKOs) and hets, respectively. Specifically, mice were treated with

631 tamoxifen on alternate days (x4) and analyzed 5 and 8 weeks later (Figure 11B). In the absence of

632 tamoxifen, there was no reduction of Gli1 levels in the peripheral nerves of $\mathrm{Gli1}^{\mathrm{CE} / \mathrm{Fl}}$;Ai9 mice

633 based on qPCR. In contrast, 5 and 8 weeks after tamoxifen treatment, Gli1 levels in iKO sciatic

634 nerves were reduced to $1-2 \%$ of littermate controls (Figure 11C).

Nerves from Gli1 iKOs revealed a striking reorganization of the nerve by MFs, which were

636 evident at 5 weeks and robust at 8 weeks (Figure 11D and E, respectively). There were no evident

637 changes in the perineurium of Gli1 iKOs based on fate mapping. At 3.5 to 4 weeks, the earliest

638 times examined, MFs were still forming (Figure 11F). Many of the MFs present at these earlier

639 times were locally peripherally and connected to the perineurium (Figure 11F, inset i). However,

640 there were also multiple examples of forming MFs that appeared to be present entirely within the

641 endoneurium that lacked an evident connection to the perineurium (Figure 11F, inset ii). This latter

642 observation suggests existing EFs within the endoneurium can reorganize to drive MF formation.

643 In complementary studies, we investigated whether re-expression of Gli1 would revert

644 MFs that had formed in the constitutive Gli1 nulls. We crossed Gli1 ${ }^{C E}$ mice to Rosa26flox-stop-flox- 
${ }_{\text {FLAG-Glil }}\left(\right.$ Rosa $\left.^{\text {Glil }}\right)$ mice (Vokes et al., 2007). These mice were further crossed to a GFP reporter i.e., Rosa26 $6^{C A G-E G F P}(\mathrm{RCE})$ allele (Figure 12A). Tamoxifen administration on alternate days (x4)

647 enabled GFP fate mapping of Gli1+ cells in hets and nulls while simultaneously driving expression 648 of a FLAG-tagged Gli1 allele in the same cells. Analysis was performed 6 weeks later (Figure

649 12B). Based on qPCR, Glil expression was restored in Glil null mice that overexpressed the 650 FLAG-Gli1 allele (Gli1 null OE) to 91\% of the levels of hets (Figure 12C). There was also a dose651 dependent, increase in Gli1 expression in Gli1 het OE mice, i.e., 81\% greater than in het controls.

652 Overexpressing Glil in hets had no overt effect on the organization of the nerves (Figure 12D). Of 653 note, despite restoration of Gli1 to essentially normal levels in the Gli1 null OE nerves, there was 654 no reduction in MFs or morphological changes in the Gli1-expressing cells compared to Gli1 nulls 655 (Figure 12E), even out to 10 weeks, the latest time point examined (data not shown).

657 MFs in healthy adult nerves over several weeks. In contrast, MFs formed during development are 658 quite stable even when Glil levels are restored to essentially normal levels during the time interval 659 examined.

\section{DISCUSSION}

We have shown that EFs, PNG, and pericytes are Gli1-expressing cells. While loss of Gli1

663 did not affect development or maintenance of the perineurium, it strongly impacted the 664 endoneurium, notably resulting in formation of MFs during development and in adult nerves 665 following iKO. These MFs are similar to those previously described in Dhh nulls (Parmantier et 666 al., 1999), a similarity that initially suggested Gli1 as a candidate effector of Dhh in the 667 endoneurium. Unexpectedly, Gli1 is persistently expressed in the EFs of Dhh nulls. As Dhh is the 
668 principal hedgehog in the PNS, these results indicate non-canonical pathways drive expression of

669 Gli1 in EFs. The presence of MFs in both Gli1 and Dhh nulls despite ongoing Gli1 expression in

670 the latter also indicates that Gli1 and Dhh function non-redundantly. Gli1 must therefore act in

671 concert with other downstream effectors of Dhh to drive acquisition of normal endoneurial

672 architecture and preclude EFs from organizing into MFs. In contrast, formation of the perineurium

673 does not require Gli1 but rather must be mediated via other effectors of Dhh, e.g., via canonical

674 signaling. Our results also extend the roster of reciprocal signaling between different cells types in

675 peripheral nerves. Thus, Gli1 null nerves exhibit altered ECM composition, likely due to

676 dysregulation of EFs, as well as non-autonomous effects on vascular organization and the

677 morphometry of axon-SC units. We consider these points further below.

678

679 Gli1 is expressed by cells with diverse embryologic origins

680 Here, we have identified EFs, PNG, and pericytes as distinct Gli1-expressing cells in 681 peripheral nerves, extending a previous study that identified EFs as Glil-expressing cells

682 (Bobarnac Dogaru et al., 2018). These three cell types have distinct embryological origins: EFs 683 arise from neural crest stem cells (Joseph et al., 2004) whereas PNG derive from Nkx2.2-positive

684 precursors that egress from the ventral spinal cord (Kucenas et al., 2008; Clark et al., 2014). The 685 origins of peripheral nerve pericytes remain to be established.

686 Gli1-positive precursors of these various populations are present in developing peripheral

687 nerves as early as E12-E15 based on in utero fate mapping (Figure 4A, B), consistent with EM 688 analysis of the cellular composition of the developing PNS (Jessen and Mirsky, 2005). SCs were 689 not labeled by the in utero fate mapping indicating that early neural crest stem cells and their glial690 restricted progeny, which express Dhh starting at E12 (Jaegle et al., 2003), are not subject to 
691 autocrine Hh signaling. These results, together with a prior study (Joseph et al., 2004), underscore

692 that distinct neural crest-derived precursors give rise to SCs and Gli1-positive EFs and that these

693 lineages become restricted prior to E15. In addition to the SC and EF lineages, a Gli1-positive

694 precursor that is not neural crest-derived is also present at this time and gives rise to PNG and/or

695 pericytes. Given that the overall nerve architecture of Glil hets and nulls is similar at P1 but

696 diverges significantly by P10 (Figure 4C-F), Glil expression is dispensable for the generation of

697 these various precursor populations in utero and functions principally in the early postnatal period.

698 Despite their distinct embryologic origins, EFs and PNG express a number of molecular

699 markers in common in addition to Glil. A recent single-cell RNA-sequencing analysis of PNS

700 cells found PDGFR $\alpha$ to be a broad marker of non-SC populations in the PNS - principally EFs

701 and PNG (Carr et al., 2019). Transcriptionally unique populations of EFs, PNG, and epineurial

702 fibroblasts were identified by this analysis. Querying this data set reveals that a significant portion

703 of each of cell type is indeed Gli1-positive. These results are therefore consistent with the nearly

704 uniform co-labeling of cells by Gli1 and PDGFR $\alpha$ (Figure 1D). In the future, fate mapping using

705 markers unique for each of these populations will enable better delineation of their embryologic

706 origins and lineage relationships than is currently possible.

707

708 Non-canonical expression of Gli1 cooperates with Dhh signaling to regulate normal

709 endoneurial development

710 As noted, we initially considered Dhh released by mSCs to be a likely driver of Gli1

711 expression in PNG and EFs. First, loss of Egr2 results in an overall decrease in Dhh with a

712 commensurate decrease in Gli1 transcripts by qPCR (Figure 2E). Second, loss of Gli1 phenocopies

713 much of the reported endoneurial phenotype of Dhh nulls: e.g., reorganization into MFs (Figure 
714 3A, B), increased capillary density (Figure 8A-E), and defective ECM (Figure 9) (Parmantier et

715 al., 1999; Chapouly et al., 2016). Third, PNG and EFs express the Patched-1 receptor (Parmantier

716 et al., 1999; Sharghi-Namini et al., 2006) and Gli2 (Extended Data Figure 1) - the latter is

717 considered an obligate canonical activator of Gli1 expression. Finally, EFs treated with Shh ligands

718 in vitro upregulate Gli1 expression (Bobarnac Dogaru et al., 2018).

719 However, our data indicates expression of Gli1 in EFs is unlikely to be downstream of Dhh

720 given that Gli1: $\beta$ Gal continues to be expressed in the EFs of Dhh nulls (Figure 2F, I). Gli1

721 transcripts persist at 44\% of control levels in P5 Dhh KO nerves, which lack detectable expression

722 of any Hh family members, strongly supporting Hh-independent expression of Gli1 in these cells

723 (Figure 2H). Determining the extent of the reduction of Gli1 expression in the P5 Dhh null EFs,

724 or if there is any reduction at all, is confounded in this qPCR analysis by the near-absence of PNG

725 and epineurial cells. These latter two cell populations likely contribute substantially to the Gli1

726 levels measured in control nerve lysates suggesting that the loss of Gli1 in EFs in the P5 Dhh nulls

727 may be nominal. Indeed, starting by at least P25, Dhh nulls exhibit normal or even increased levels

728 of Gli1 (Figure 2K) further underscoring that Glil expression is independent of Dhh. A modest

729 increase may result from increased numbers of Gli1-positive cells akin to that seen in the Gli1

730 nulls (Fig. 5C)

731 We also considered neurons as a potential source of hedgehog ligands within peripheral

732 nerves. Shh is expressed by a subset of dorsal root ganglion neurons and is transported into their

733 distal axons, driving Gli1 expression in the surrounding follicular epithelium (Brownell et al.,

734 2011). This potential source of Shh would not be detected by qPCR of nerves as its

735 transcripts/synthesis reside in the soma. However, Shh conveyed by axons is an unlikely driver of

736 Gli1 in EFs in healthy nerves. First, it is not known if Shh can be released along the length of axons 
737 or if it is only released at their termini. Even if Shh is released en passant, axons are wrapped by

738 Remak or mSC processes along their length, which would be expected to impede access to

739 endoneurial cells. In follow-up studies, we carried out nerve transection to remove axons as a

740 potential source of Hh ligands (Brownell et al., 2011) and 1 week later, Gli1: $\beta$ Gal continued to be

741 expressed in cells in the distal (data not shown). These latter results are potentially ambiguous as

742 expression of Shh is reported to be upregulated in SCs following nerve injury (Hashimoto et al., 743 2008).

744 Thus, normal endoneurial development requires co-incident signaling from non-

745 canonically expressed Gli1 and from other (non-Gli1) signals downstream of Dhh. The ligands

746 and pathways that drive non-canonical Glil expression in EFs of the Dhh nulls are not known.

747 Candidate pathways include MAPK/ERK (Po et al., 2017; Hasan et al., 2020) and/or TGF $3 /$ SMAD

748 signaling pathways (Dennler et al., 2007). The pathways downstream of Dhh likely include

749 canonical, Smo-dependent generation of the Gli2A transcriptional activator or inactivation of the

750 Gli3R repressor (Ingham and McMahon, 2001). Gli1 and Gli2 were previously shown to have

751 significant functional redundancy in vivo (Bai and Joyner, 2001) and Gli2 is known to physically

752 and functionally interact with Gli1 to coordinately regulate transcription (Tolosa et al., 2020),

753 suggesting a mechanism for coincident canonical and non-canonical control of EF differentiation,

754 respectively.

755

756 Formation and Stability of Minifascicles

757 A long-standing question is what is the cell of origin that gives rise to MFs. Prior studies

758 had suggested PNG as a potential source of MFs based on the morphological and marker

759 similarities of cells in MFs to PNG (Burkel, 1967; Parmantier et al., 1999). Results from this study 
760 indicate that EFs are a much more likely cellular source of these structures. In the Dhh nulls, there

761 is almost no perineurium (Figure 2F), yet despite the absence of PNG, formation of MFs is robust

762 (Figure 2I). In Gli1 nulls, the perineurium appears normal (Figure 3E), yet endoneurial not

763 perineurial, Glil-positive cells exhibit increased proliferation in these mice (Figure 5D). There are

764 also decreased numbers of free EFs in the Glil nulls (Figure 5G). These latter results suggest

765 dividing EFs are recruited to form MFs. In addition, EFs undergo a morphological transformation

766 postnatally in the Gli1 nulls. Unlike Gli1 het EFs, which gradually retract processes potentially in

767 response to Dhh released postnatally by $\mathrm{mSCs}$, these processes persist and extend further in the

768 Gli1 nulls, eventually interdigitating with each other (Figure 4F, H). A similar morphological

769 transformation of EFs was evident in adult Glil iKOs at the onset of MF formation, where they

770 often lacked an apparent connection to the perineurium (Figure 11F). Compellingly, MFs that

771 initially form in both the Dhh and Gli1 nulls express EF but not PNG markers (Figure 7).

772 Taken together, these results strongly support an EF origin of MFs. As MFs become more

773 robust over time, they express PNG markers (e.g., Glut-1), and become fully integrated with the

774 perineurium. Expression of PNG markers in mature MFs could reflect invasion of MFs by PNG

775 over time. Alternatively, EFs may upregulate PNG markers as MFs mature due to density-

776 dependent effects on expression (Extended data Figure 2). Consistent with the latter possibility,

777 i.e., that EFs can acquire PNG characteristics, EFs appear able to regenerate a full perineurial

778 sheath following microsurgical stripping of the perineurium (Nesbitt and Acland, 1980). Similarly,

779 purified fibroblasts added to myelinating SC/neuron cocultures form perineurial-like structures

780 (Bunge et al., 1989).

781 Following injury/transection, MFs surround SC basal lamina tubes (i.e., Bungner Bands)

782 in the distal stumps (Morris et al., 1972; Röyttä et al., 1987). Our findings thus suggest resident 
783 EFs are likely to form MFs after nerve injury (Röyttä et al., 1987; Röyttä and Salonen, 1988; Vallat

784 et al., 1988) or in neuropathies (Baldinotti et al., 2018). An EF source is consistent with a prior

785 study showing that MFs assemble in transected rat sciatic nerves despite prior mechanical removal

786 of the local perineurium (Terho et al., 2002). Recent data demonstrates MFs in injured nerves arise

787 from Gli1-positive cells (Bobarnac Dogaru et al., 2018; BZ, JLS unpublished). Future studies using

788 cell specific markers will be useful to determine if EFs also form injury-induced MFs.

789 We have also shown that $\mathrm{iKO}$ of Gli1 in adult nerves is sufficient to drive MF formation

790 within several weeks (Figure 11). This result supports the notion that reductions of Dhh and/or

791 Gli1 signaling that ensue with injury/SC dedifferentiation contribute to MF formation in

792 pathological settings. Once formed, MFs appear quite stable as re-expression of Gli1 in adult Gli1

793 nulls failed to reverse the MF phenotype after 10 weeks (Figure 12). Previous work has shown that

794 MFs formed following nerve transection injury are also very stable. MFs tend to disappear $\sim 20$

795 weeks with successful reinnervation of the transected nerve (Röyttä and Salonen, 1988),

796 suggesting that these structures can undergo slow disassembly with SC redifferentiation driven by

797 axonal signals.

798

799 Potential effects of MFs on peripheral nerve function

800 The findings in the Glil nulls raise the question of whether there are pathological or

801 functional consequences of reorganizing nerves into MFs. Normally, motor and sensory fibers in

802 peripheral nerves maintain a high degree of somatotopy despite frequent anastomoses between

803 perineurial sheaths. Thus, motor fibers for specific muscle groups and sensory fibers for specific

804 cutaneous areas tend to remain grouped as fascicles or within fascicles along the length of

805 peripheral nerves (Badia et al., 2010; Mioton et al., 2019). In the case of the Gli1 nulls, SBF-SEM 
806 revealed that the cellular sheaths forming MFs are not confined to a fixed set of axons but rather

807 anastomose along their length (see Extended Data Video 1). As the Gli1 nulls do not exhibit any

808 gross functional deficits that would be expected from mistargeting of axons, fascicles seem likely

809 to retain their normal somatotopy despite subdivision into fascicles that contain as few as $1-2$

810 axons.

811 Prospective functional consequences of MFs have been considered primarily in the context

812 of nerve injury and are extrapolated from the normal functions of the perineurium, which they

813 resemble. MFs are thought to restore the tissue barrier function that is lost with the disruption of

814 the perineurium in mechanical injury (Ahmed and Weller, 1979). In agreement, MFs form tight

815 junctions and provide a competent barrier against infiltration of injected tracers into fascicles

816 (Figure 3G-I). Akin to the perineurium, MFs are likely to protect against stretch injury (Schraut et

817 al., 2016), which damaged peripheral nerve/distal stumps may be particularly susceptible to. Also

818 similar to the perineurium, MFs may protect nerve fibers from immunologic damage, including

819 complement, and help maintain homeostatic intraneural pressure and metabolism (Zochodne,

820 2009; Weerasuriya and Mizisin, 2010).

821

822 Nerve sheath and barrier development is Dhh-dependent but Gli1-independent: implications

823 for axonal degeneration

824 A striking finding of this study is that while Dhh nulls exhibit major defects of the 825 perineurium and epineurium (Parmantier et al., 1999), the Gli1 nulls do not (Figure 3D-F). Thus, 826 PNG development requires Dhh signals potentially via canonical signaling that is Gli1827 independent, e.g., via Gli2A. In agreement, a recent study examining regeneration after nerve 828 injury with a Gli $1^{\text {CreERT2 }}$ driven $\mathrm{cKO}$ of Smo reported the perineurium failed to reform (Yamada et 
829 al., 2021). Whether expression of Gli1 itself is canonical or non-canonical in PNG is unclear as

830 there are essentially no PNG to monitor in the $\mathrm{Dhh}^{-/-} ; \mathrm{Gli1}{ }^{\mathrm{LacZ} /+}$ mice. Future studies with inducible

831 KOs of Smo or Dhh after the perineurium has formed will be useful to determine if Gli1 expression

832 in PNG is canonical or not.

An additional difference between Dhh and Gli1 nulls is that the former exhibit axonal

834 degeneration/regeneration with increased age (Sharghi-Namini et al., 2006) whereas Gli1 nulls do

835 not, even at 18 months (data not shown). This difference suggests the aberrant perineurium of the

836 Dhh nulls, with its associated loss of BNB function (Sharghi-Namini et al., 2006), underlies the

837 axonal degeneration in these mice rather than the re-organization into MFs or ECM changes, which

838 are seen in both Dhh and Glil nulls. Likewise a defective perineurium and BNB may account for

839 the axonal injury and severe peripheral neuropathy seen in patients with Dhh mutations, despite

840 their designation as minifascicle neuropathies (Baldinotti et al., 2018). Macrophage numbers are

841 increased in the Dhh (Sharghi-Namini et al., 2006) but not significantly in the Gli1 nulls (Figure

$8428 \mathrm{H}-\mathrm{J})$ nerves, potentially resulting from the aberrant $\mathrm{BNB}$ in the former. Whether this

843 inflammation contributes to and/or is a consequence of axonal degeneration in these animals is not

844 yet known.

845

846 Gli1 demarcates peripheral nerve pericytes and regulates vascular organization

847 There is a striking expansion of the nerve vasculature in Glil nulls which is closely

848 associated with MF formation. The perivascular Gli1+ cells in the PNS are plausible candidates to

849 direct this remodeling of the vasculature as they are known to directly regulate angiogenesis by

850 developing ECs (Bergers and Song, 2005). Indeed, in a recent study (Chen et al., 2020), genetic

851 ablation of Gli1-positive perivascular mesenchymal stem cells surrounding capillaries in bone 
852 resulted in defective angiogenesis in both healthy and injured bones. This pro-angiogenic effect is

853 believed to be mediated by HIF-1 $\alpha$ signaling (Chen et al., 2020). Additionally, a recent report

854 identified Gli1-expressing EFs as a source of VEGF in the setting of nerve injury (Faniku et al.,

855 2021). Our data are consistent with this possibility given the close association of the EF-derived

856 MFs and the vasculature (Figure 8A-E and Extended data video 1). The role of this increased

857 vascularization is not known, but may provide enhanced metabolic support to nerves partitioned

858 by MFs by compensating for any constraints on nutrient diffusion within the endoneurium imposed

859 by MFs. In potential agreement, increasing angiogenesis via VEGF gene therapy improves axonal

860 survival following injury (Pereira Lopes et al., 2011).

861

862 Myelinating SCs regulate Gli1 levels and assembly of peripheral nerve compartments

863 We have corroborated that Egr2 activity regulates Dhh production by adult SCs, in 864 agreement with a prior report (Jang et al., 2006). Thus, Dhh levels are reduced by 50\% in Egr2

865 conditional KOs (Fig. 2E). This residual expression in the Egr2 nulls indicates other transcriptional

866 activators must also regulate Dhh. One such transcription factor is Sox 10, which directly regulates

867 Dhh expression (Küspert et al., 2012), and thereby the perineurium, and cooperates with Egr2 to

868 drive myelination.

As noted, there is also a commensurate reduction of Dhh and Gli1 in the Egr2 nulls. These

870 results indicate Glil expression in the perineurium and endoneurium is regulated by factor(s)

871 released from mSCs, coordinating Dhh and Gli1 expression with myelination. Interestingly, in the

872 adult Egr2 nulls, EFs partially but incompletely organize as MFs (Figure 2D). This incomplete MF

873 formation is consistent with significant, residual expression of both Dhh and Gli1 in these mice

874 potentially driven by Sox10 expression. In contrast, MFs are a prominent feature of many 
875 dysmyelinating SC mouse mutations (Feltri et al., 2002; Darbas et al., 2004; Yu et al., 2005; Grove

876 et al., 2007; Monk et al., 2011). Substantial reductions of Egr2 in these mouse mutants, with

877 resulting reductions of Dhh and Gli1, likely contributes to their formation of MFs.

878

879 Reciprocal intercellular signaling during PNS development

880 Our results, together with prior reports, underscore the rich, reciprocal set of intercellular

881 signals that coordinates development of the various cellular compartments of peripheral nerves.

882 Thus, axonal signals, including neuregulin, upregulate Egr2, which cooperates with Sox10 to

883 initiate myelination (Kao et al., 2009; He et al., 2010). This in turn drives SC production of Dhh

884 and upregulation of Gli1 in cellular targets to regulate nerve fasciculation, development of the

885 vasculature, and ECM production. Our results further indicate these endoneurial changes

886 reciprocally feedback to regulate axon-SC units. This is evidenced by the smaller axons, thicker

887 myelin, and enhanced segregation of axons in Remak fibers in the Gli1 nulls (Figure 10).

888 Similar effects on myelinated axon diameters and Remak sorting, but not myelination, were

889 described previously in Dhh mutants (Sharghi-Namini et al., 2006). The changes in Remak bundles

890 in the Dhh nulls were considered a direct effect of Dhh on Remak SCs signaling via Ptch2

891 (Bajestan et al., 2006). As neither mSCs or Remak SCs express Gli1, any effects on myelinated

892 and Remak fibers in the Gli1 nulls - and by inference potentially in the Dhh mutants - must be SC

893 non-autonomous. Thus, signals originating in Glil null EFs, pericytes, and/or PNG must account

894 for the altered morphology of these axon-SC units. This notion agrees with earlier studies in 895 zebrafish that implicate PNG in regulating early SC development (Kucenas et al., 2008; Binari et 896 al., 2013). 
899 (Figure 9). These components may regulate nerve fiber packing density (Figure 10A-C) and 900 contribute directly to the SC basal lamina or indirectly enhance its production (Obremski et al., 901 1993). The basal lamina is an important positive and negative regulator of SC myelination (Heller 902 et al., 2014; Ghidinelli et al., 2017). Additionally, fibrillary collagens, which are reduced in Gli1 903 nulls, normally confer mechanical stability to peripheral nerves (Ushiki and Ide, 1986). Loss of 904 these ECM components may alter nerve stiffness in the Gli1 nulls, impacting mechanical signaling 905 that regulates SC differentiation (Sophie et al., 2019). Finally, there is a rich array of paracrine 906 signals released by EFs, whose expression is affected by nerve injury (Toma et al., 2020), that may 907 likewise be altered in the Gli1 nulls impacting SCs. A recent study identified EFs in regenerating 908 nerves as a source of soluble neuregulin (Fornasari et al., 2020), an important signal that promotes 909 the SC repair phenotype essential for nerve regeneration (Stassart et al., 2013). Future studies 910 utilizing RNA-seq and proteomic analyses to elucidate further the nature of the peripheral nerve 911 signals that impinge on SCs will be of considerable interest. 


\section{REFERENCES}

915

Ahmed AM, Weller RO (1979) The blood-nerve barrier and reconstitution of the perineurium following nerve grafting. Neuropathology and Applied Neurobiology 5:469-483.

Ahn S, Joyner AL (2004) Dynamic Changes in the Response of Cells to Positive Hedgehog Signaling during Mouse Limb Patterning. Cell 118:505-516.

Badia J, Pascual-Font A, Vivó M, Udina E, Navarro X (2010) Topographical distribution of motor fascicles in the sciatic-tibial nerve of the rat. Muscle \&amp; Nerve 42:192-201.

Bai CB, Auerbach W, Lee JS, Stephen D, Joyner AL (2002) Gli2, but not Gli1, is required for initial Shh signaling and ectopic activation of the Shh pathway. Development 129:47534761.

Bai CB, Joyner AL (2001) Gli1 can rescue the in vivo function of Gli2. Development 128:51615172.

Bajestan SN, Umehara F, Shirahama Y, Itoh K, Sharghi-Namini S, Jessen KR, Mirsky R, Osame M (2006) Desert hedgehog-patched 2 expression in peripheral nerves during Wallerian degeneration and regeneration. Journal of Neurobiology 66:243-255.

Baldinotti F, Cavallaro T, Dati E, Baroncelli GI, Bertini V, Valetto A, Massart F, Fabrizi GM, Zanette G, Peroni D, Bertelloni S (2018) Novel Familial Variant of the Desert Hedgehog Gene: Clinical Findings in Two Sisters with 46,XY Gonadal Dysgenesis or 46,XX Karyotype and Literature Review. HRP 89:141-149.

Bell MA, Weddell AG (1984a) A descriptive study of the blood vessels of the sciatic nerve in the rat, man and other mammals. Brain 107 ( Pt 3):871-898.

Bell MA, Weddell AGM (1984b) A morphometric study of intrafascicular vessels of mammalian sciatic nerve. Muscle \&amp; Nerve 7:524-534.

Bergers G, Song S (2005) The role of pericytes in blood-vessel formation and maintenance. Neuro-oncology 7:452-464.

Binari LA, Lewis GM, Kucenas S (2013) Perineurial glia require Notch signaling during motor nerve development but not regeneration. J Neurosci 33:4241-4252.

942 Bitgood MJ, Shen L, McMahon AP (1996) Sertoli cell signaling by Desert hedgehog regulates 943 the male germline. Current Biology 6:298-304.

944 Bobarnac Dogaru GL, Juneja SC, Shokrani A, Hui RY, Chai Y, Pepper J-P (2018) The role of 945 Hedgehog-responsive fibroblasts in facial nerve regeneration. Experimental Neurology. 
Briscoe J, Thérond PP (2013) The mechanisms of Hedgehog signalling and its roles in development and disease. Nat Rev Mol Cell Biol 14:416-429.

Brownell I, Guevara E, Bai CB, Loomis CA, Joyner AL (2011) Nerve-derived sonic hedgehog defines a niche for hair follicle stem cells capable of becoming epidermal stem cells. Cell Stem Cell 8:552-565.

Bunge MB, Wood PM, Tynan LB, Bates ML, Sanes JR (1989) Perineurium originates from fibroblasts: demonstration in vitro with a retroviral marker. Science 243:229-231.

Burkel WE (1967) The histological fine structure of perineurium. Anat Rec 158:177-189.

Carr MJ, Toma JS, Johnston APW, Steadman PE, Yuzwa SA, Mahmud N, Frankland PW, Kaplan DR, Miller FD (2019) Mesenchymal Precursor Cells in Adult Nerves Contribute to Mammalian Tissue Repair and Regeneration. Cell Stem Cell 24:240-256.e249.

Chapouly C, Yao Q, Vandierdonck S, Larrieu-Lahargue F, Mariani JN, Gadeau A-P, Renault MA (2016) Impaired Hedgehog signalling-induced endothelial dysfunction is sufficient to induce neuropathy: implication in diabetes. Cardiovasc Res 109:217-227.

Chen J, Li M, Liu A-Q, Zheng C-X, Bao L-H, Chen K, Xu X-L, Guan J-T, Bai M, Zhou T, Sui B-D, Li D-H, Jin Y, Hu C-H (2020) Gli1+ Cells Couple with Type H Vessels and Are Required for Type H Vessel Formation. Stem Cell Reports 15:110-124.

Clark JK, O'keefe A, Mastracci TL, Sussel L, Matise MP, Kucenas S (2014) Mammalian Nkx2.2 +perineurial glia are essential for motor nerve development. Dev Dyn 243:1116-1129.

Darbas A, Jaegle M, Walbeehm E, van den Burg H, Driegen S, Broos L, Uyl M, Visser P, Grosveld F, Meijer D (2004) Cell autonomy of the mouse claw paw mutation. Developmental Biology 272:470-482.

Dennler S, André J, Alexaki I, Li A, Magnaldo T, Dijke ten P, Wang X-J, Verrecchia F, Mauviel A (2007) Induction of Sonic Hedgehog Mediators by Transforming Growth Factor- $\beta$ : Smad3-Dependent Activation of Gli2 and Gli1 Expression In vitro and In vivo. Cancer Res 67:6981-6986.

Dessaud E, McMahon AP, Briscoe J (2008) Pattern formation in the vertebrate neural tube: a sonic hedgehog morphogen-regulated transcriptional network. Development 135:2489-2503.

Du N, Kwon H, Li P, West EE, Oh J, Liao W, Yu Z, Ren M, Leonard WJ (2014) EGR2 is critical for peripheral naïve T-cell differentiation and the T-cell response to influenza. Proc Natl Acad Sci USA 111:16484-16489.

Faniku C, Kong W, He L, Zhang M, Lilly G, Pepper JP (2021) Hedgehog signaling promotes endoneurial fibroblast migration and Vegf-A expression following facial nerve injury. Brain Res 1751:147204. 
Feltri ML, D'antonio M, PREVITALI S, FASOLINI M, MESSING A, Wrabetz L (1999) P0-Cre Transgenic Mice for Inactivation of Adhesion Molecules in Schwann Cells. Ann N Y Acad Sci 883:116-123.

Feltri ML, Graus Porta D, Previtali SC, Nodari A, Migliavacca B, Cassetti A, Littlewood-Evans A, Reichardt LF, MESSING A, Quattrini A, Mueller U, Wrabetz L (2002) Conditional disruption of beta 1 integrin in Schwann cells impedes interactions with axons. The Journal of Cell Biology 156:199-209.

Feltri ML, Poitelon Y, Previtali SC (2016) How Schwann Cells Sort Axons. The Neuroscientist 22:252-265.

Flores AJ, Lavernia CJ, Owens PW (2000) Anatomy and physiology of peripheral nerve injury and repair. Am J Orthop 29:167-173.

Fornasari BE, Soury El M, Nato G, Fucini A, Carta G, Ronchi G, Crosio A, Perroteau I, Geuna S, Raimondo S, Gambarotta G (2020) Fibroblasts Colonizing Nerve Conduits Express High Levels of Soluble Neuregulin1, a Factor Promoting Schwann Cell Dedifferentiation. Cells 9:1366.

Gerber D, Pereira JA, Gerber J, Tan G, Dimitrieva S, Yángüez E, Suter U (2021) Transcriptional profiling of mouse peripheral nerves to the single-cell level to build a sciatic nerve ATlas (SNAT). Elife 10:e58591

Ghidinelli M, Poitelon Y, Shin YK, Ameroso D, Williamson C, Ferri C, Pellegatta M, Espino K, Mogha A, Monk K, Podini P, Taveggia C, Nave K-A, Wrabetz L, Park HT, Feltri ML (2017) Laminin 211 inhibits protein kinase A in Schwann cells to modulate neuregulin 1 type III-driven myelination Emery B, ed. PLoS Biol 15:e2001408.

Grove M, Komiyama NH, Nave K-A, Grant SG, Sherman DL, Brophy PJ (2007) FAK is required for axonal sorting by Schwann cells. The Journal of Cell Biology 176:277-282.

Hasan MR, Takatalo M, Ma H, Rice R, Mustonen T, Rice DP (2020) RAB23 coordinates early osteogenesis by repressing FGF10-pERK1/2 and GLI1. eLife 9.

Hashimoto M, Ishii K, Nakamura Y, Watabe K, Kohsaka S, Akazawa C (2008) Neuroprotective effect of sonic hedgehog up-regulated in Schwann cells following sciatic nerve injury. J Neurochem 107:918-927.

He Y, Kim JY, Dupree J, Tewari A, Melendez-Vasquez C, Svaren J, Casaccia P (2010) Yy1 as a molecular link between neuregulin and transcriptional modulation of peripheral myelination. Nat Neurosci 13:1472-1480.

Heller BA, Ghidinelli M, Voelkl J, Einheber S, Smith R, Grund E, Morahan G, Chandler D, Kalaydjieva L, Giancotti F, King RH, Fejes-Toth AN, Fejes-Toth G, Feltri ML, Lang F, Salzer JL (2014) Functionally distinct PI 3-kinase pathways regulate myelination in the peripheral nervous system. The Journal of Cell Biology 204:1219-1236. 
Ingham PW, McMahon AP (2001) Hedgehog signaling in animal development: paradigms and principles. Genes \& Development 15:3059-3087.

Jaegle M, Ghazvini M, Mandemakers W, Piirsoo M, Driegen S, Levavasseur F, Raghoenath S, Grosveld F, Meijer D (2003) The POU proteins Brn-2 and Oct-6 share important functions in Schwann cell development. Genes \& Development 17:1380-1391.

Jang S-W, LeBlanc SE, Roopra A, Wrabetz L, Svaren J (2006) In vivo detection of Egr2 binding to target genes during peripheral nerve myelination. J Neurochem 98:1678-1687.

Jessen KR, Mirsky R (2005) The origin and development of glial cells in peripheral nerves. Nat Rev Neurosci 6:671-682.

Joseph NM, Mukouyama Y-S, Mosher JT, Jaegle M, Crone SA, Dormand E-L, Lee K-F, Meijer D, Anderson DJ, Morrison SJ (2004) Neural crest stem cells undergo multilineage differentiation in developing peripheral nerves to generate endoneurial fibroblasts in addition to Schwann cells. Development 131:5599-5612.

Jung S, Aliberti J, Graemmel P, Sunshine MJ, Kreutzberg GW, Sher A, Littman DR (2000) Analysis of Fractalkine Receptor CX3CR1 Function by Targeted Deletion and Green Fluorescent Protein Reporter Gene Insertion. Molecular and Cellular Biology 20:4106-4114.

Kao S-C, Wu H, Xie J, Chang C-P, Ranish JA, Graef IA, Crabtree GR (2009) Calcineurin/NFAT signaling is required for neuregulin-regulated Schwann cell differentiation. Science 323:651-654.

Kristensson K, Olsson Y (1971) The perineurium as a diffusion barrier to protein tracers. Acta Neuropathol 17:127-138.

Kucenas S, Takada N, Park H-C, Woodruff E, Broadie K, Appel B (2008) CNS-derived glia ensheath peripheral nerves and mediate motor root development. Nat Neurosci 11:143-151.

Küspert M, Weider M, Müller J, Hermans-Borgmeyer I, Meijer D, Wegner M (2012) Desert hedgehog links transcription factor Sox10 to perineurial development. J Neurosci 32:54725480 .

Lauth M, Bergström A, Shimokawa T, Toftgård R (2007) Inhibition of GLI-mediated transcription and tumor cell growth by small-molecule antagonists. Proc Natl Acad Sci USA 104:8455-8460.

Madisen L, Zwingman TA, Sunkin SM, Oh SW, Zariwala HA, Gu H, Ng LL, Palmiter RD, Hawrylycz MJ, Jones AR, Lein ES, Zeng H (2010) A robust and high-throughput Cre reporting and characterization system for the whole mouse brain. Nat Neurosci 13:133-140.

Mioton LM, Dumanian GA, la Garza De M, Ko JH (2019) Histologic Analysis of Sensory and Motor Axons in Branches of the Human Brachial Plexus. Plast Reconstr Surg 144:13591368. 
Monk KR, Oshima K, Jörs S, Heller S, Talbot WS (2011) Gpr126 is essential for peripheral nerve development and myelination in mammals. Development 138:2673-2680.

Morris JH, Hudson AR, Weddell G (1972) A study of degeneration and regeneration in the divided rat sciatic nerve based on electron microscopy. IV. Changes in fascicular microtopography, perineurium and endoneurial fibroblasts. Z Zellforsch Mikrosk Anat 124:165-203.

Murphy P, Topilko P, Schneider-Maunoury S, Seitanidou T, Baron-Van Evercooren A, Charnay P (1996) The regulation of Krox-20 expression reveals important steps in the control of peripheral glial cell development. Development 122:2847-2857.

Nesbitt JA, Acland RD (1980) Histopathological changes following removal of the perineurium. J Neurosurg 53:233-238.

Obremski VJ, Johnson MI, Bunge MB (1993) Fibroblasts are required for Schwann cell basal lamina deposition and ensheathment of unmyelinated sympathetic neurites in culture. $\mathrm{J}$ Neurocytol 22:102-117.

Ochoa C, Spinel CM (2010) Cell Cultures of the Sciatic Nerve and Dorsal Root Ganglia from Adult Mouse. Acta Biológica Colombiana.

Olsson Y (1968) Topographical differences in the vascular permeability of the peripheral nervous system. Acta Neuropathol 10:26-33.

Olsson Y (1990) Microenvironment of the peripheral nervous system under normal and pathological conditions. Crit Rev Neurobiol 5:265-311.

Park HL, Bai C, Platt KA, Matise MP, Beeghly A, Hui CC, Nakashima M, Joyner AL (2000) Mouse Gli1 mutants are viable but have defects in SHH signaling in combination with a Gli2 mutation. Development 127:1593-1605.

Parmantier E, Lynn B, Lawson D, Turmaine M, Namini SS, Chakrabarti L, McMahon AP, Jessen KR, Mirsky R (1999) Schwann Cell-Derived Desert Hedgehog Controls the Development of Peripheral Nerve Sheaths. Neuron 23:713-724.

Peltonen J, Jaakkola S, Virtanen I, Pelliniemi L (1987) Perineurial cells in culture. An immunocytochemical and electron microscopic study. Lab Invest 57:480-488.

Peltonen S, Alanne M, Peltonen J (2013) Barriers of the peripheral nerve. Tissue Barriers 1:e24956.

Pereira Lopes FR, Lisboa BCG, Frattini F, Almeida FM, Tomaz MA, Matsumoto PK, Langone F, Lora S, Melo PA, Borojevic R, Han SW, Martinez AMB (2011) Enhancement of sciatic nerve regeneration after vascular endothelial growth factor (VEGF) gene therapy. Neuropathology and Applied Neurobiology 37:600-612. 
Po A et al. (2017) Noncanonical GLI1 signaling promotes stemness features and in vivo growth in lung adenocarcinoma. Oncogene 36:4641-4652.

Richard L, Topilko P, Magy L, Decouvelaere A-V, Charnay P, Funalot B, Vallat J-M (2012) Endoneurial fibroblast-like cells. Journal of Neuropathology \& Experimental Neurology 71:938-947.

Richard L, Védrenne N, Vallat J-M, Funalot B (2014) Characterization of Endoneurial Fibroblast-like Cells from Human and Rat Peripheral Nerves. J Histochem Cytochem 62:424-435.

Röyttä M, Salonen V (1988) Long-term endoneurial changes after nerve transection. Acta Neuropathol 76:35-45.

Röyttä M, Salonen V, Peltonen J (1987) Reversible endoneurial changes after nerve injury. Acta Neuropathol 73:323-329.

Salzer JL (2015) Schwann Cell Myelination. Cold Spring Harb Perspect Biol 7:a020529.

Schraut NB, Walton S, Bou Monsef J, Shott S, Serici A, Soulii L, Amirouche F, Gonzalez MH, Kerns JM (2016) What Protects Certain Nerves from Stretch Injury? Anat Rec (Hoboken) 299:111-117.

Sharghi-Namini S, Turmaine M, Meier C, Sahni V, Umehara F, Jessen KR, Mirsky R (2006) The structural and functional integrity of peripheral nerves depends on the glial-derived signal desert hedgehog. J Neurosci 26:6364-6376.

Sophie B, Jacob H, Jordan VJS, Yungki P, Laura FM, Yannick P (2019) YAP and TAZ Regulate Cc2d1b and Pur $\beta$ in Schwann Cells. Front Mol Neurosci 12:1047.

Stassart RM, Fledrich R, Velanac V, Brinkmann BG, Schwab MH, Meijer D, Sereda MW, Nave K-A (2013) A role for Schwann cell-derived neuregulin-1 in remyelination. Nat Neurosci $16: 48-54$.

Terho PM, Vuorinen VS, Röyttä M (2002) The endoneurial response to microsurgically removed epi- and perineurium. J Peripher Nerv Syst 7:155-162.

Tolosa EJ et al. (2020) GLI1/GLI2 functional interplay is required to control Hedgehog/GLI targets gene expression. Biochem J 477:3131-3145.

Toma JS, Karamboulas K, Carr MJ, Kolaj A, Yuzwa SA, Mahmud N, Storer MA, Kaplan DR, Miller FD (2020) Peripheral Nerve Single Cell Analysis Identifies Mesenchymal Ligands that Promote Axonal Growth. eNeuro:ENEURO.0066-20.2020.

Topilko P, Schneider-Maunoury S, Levi G, Baron-Van Evercooren A, Chennoufi AB, Seitanidou T, Babinet C, Charnay P (1994) Krox-20 controls myelination in the peripheral nervous system. Nature 371:796-799. 
Tserentsoodol N, Shin BC, Koyama H, Suzuki T, Takata K (1999) Immunolocalization of tight junction proteins, occludin and ZO-1, and glucose transporter GLUT1 in the cells of the blood-nerve barrier. Arch Histol Cytol 62:459-469.

Umehara F, Tate G, Itoh K, Yamaguchi N, Douchi T, Mitsuya T, Osame M (2000) A Novel Mutation of desert hedgehog in a Patient with 46,XY Partial Gonadal Dysgenesis Accompanied by Minifascicular Neuropathy. The American Journal of Human Genetics 67:1302-1305.

Ushiki T, Ide C (1986) Three-dimensional architecture of the endoneurium with special reference to the collagen fibril arrangement in relation to nerve fibers. Arch Histol Jpn 49:553-563.

Vallat JM, Leboutet MJ, Loubet A, Hugon J, Moreau JJ (1988) Effects of glycerol injection into rat sciatic nerve. Muscle \&amp; Nerve 11:540-545.

Vokes SA, Ji H, McCuine S, Tenzen T, Giles S, Zhong S, Longabaugh WJR, Davidson EH, Wong WH, McMahon AP (2007) Genomic characterization of Gli-activator targets in sonic hedgehog-mediated neural patterning. Development 134:1977-1989.

Weerasuriya A, Mizisin AP (2010) The Blood-Nerve Barrier: Structure and Functional Significance. In: The Blood-Brain and Other Neural Barriers, pp 149-173 Methods in Molecular Biology. Totowa, NJ: Humana Press.

Wilson CW, Chuang P-T (2010) Mechanism and evolution of cytosolic Hedgehog signal transduction. Development 137:2079-2094.

Wolman M, Klatzo I, Chui E, Wilmes F, Nishimoto K, Fujiwara K, Spatz M (1981) Evaluation of the dye-protein tracers in pathophysiology of the blood-brain barrier. Acta Neuropathol 54:55-61.

Yamada Y, Nihara J, Trakanant S, Kudo T, Seo K, Iida I, Izumi K, Kurose M, Shimomura Y, Terunuma M, Maeda T, Ohazama A (2021) Perivascular Hedgehog responsive cells play a critical role in peripheral nerve regeneration via controlling angiogenesis. Neurosci Res.

Yu W-M, Feltri ML, Wrabetz L, Strickland S, Chen Z-L (2005) Schwann cell-specific ablation of laminin gammal causes apoptosis and prevents proliferation. J Neurosci 25:4463-4472.

Zochodne DW (2009) Neurobiology of Peripheral Nerve Regeneration. Cambridge: Cambridge University Press. 


\section{FIGURE LEGENDS}

Figure 1: PNG, EF, and pericytes are Gli1-positive PNS cells

(A) Schematic of a peripheral nerve highlighting three cellular compartments: the epineurium, which surround nerve fascicles and delineate the endoneurium, which contains axons (orange) that are either individually myelinated by mSCs (sheath is dark blue) or multiply ensheathed by Remak SCs (light blue), and scattered endoneurial fibroblasts (EF, green). These fascicles are surrounded and bound together by the epineurium. (B) Cross-section and (C) longitudinal section showing fate mapping of the perineurium (arrows) and scattered endoneurial cells (arrowheads) of adult Gli1 $^{C E /+} ; A i 9$ (Gli1 het) sciatic nerves. (D) Gli1:tdT fate mapping (red) overlaps almost entirely with PDGFR $\alpha$ (green), a marker of EFs and PNG. (E) EFs labeled with Gli1:tdT (red) co-express

NG2 (green), and PDGFR $\alpha$ (blue). (F) Immuno-EM to detect GFP in Gli1 ${ }^{C E /+} ; e G F P$ fate mapped $\mu \mathrm{m},(\mathrm{K}) 3 \mu \mathrm{m}$. 
1173 (A) A cross section of Gli ${ }^{\text {LacZ/+ }}$ control nerve stained for $\beta$ Gal (green) and PDGFR $\alpha$ (red) co-

1174 labels EFs (arrowhead) and PNG (arrow). (B) EM of an adult control nerve reveals normal

1175 morphology of an EF (arrowhead) and of myelinated axons. (C) A cross section from an Egr2 cKO

1176 crossed to Gli1 ${ }^{\mathrm{LacZ} /+}$ shows $\beta \mathrm{Gal} / \mathrm{PDGFR} \alpha$ co-labeling of both EFs (arrowhead) and PNG (arrow).

1177 (D) EM shows all axons in the Egr2 cKOs are ensheathed by SCs, which are arrested at the

1178 promyelinating stage. By EM, EF morphology is significantly altered with increased process

1179 extension (D, arrowhead). (E) qPCR performed on sciatic nerves of P50 controls and Egr2 cKOs

1180 shows a $>99 \%$ reduction in Egr2 mRNA and a $\sim 50 \%$ reduction of both Dhh and Gli1 mRNA.

1181 Egr2: Ctrl $(1.00 \pm 0.97)$ vs KO $(0.002 \pm 0.00), \mathrm{p}=0.0092 ;$ Dhh: Ctrl $(1.00 \pm 0.91)$ vs KO $(0.56 \pm$

1182 0.012), $\mathrm{p}=0.037$; Gli1: $\mathrm{Ctrl}(1.00 \pm 0.13)$ vs $\mathrm{KO}(0.44 \pm 0.06), \mathrm{p}=0.03$. (F) Cross section from P5

1183 Dhh KO crossed to Gli1 ${ }^{\mathrm{LacZ} /+}$ revealed the absence of a perineurium in Dhh KOs (arrow), but the

1184 persistence of many Gli1: $\beta$ Gal-positive cells (green, arrowheads) and extensive PDGFR $\alpha$-positive

1185 minifascicles (MFs, red). (G) EM of P5 Dhh KOs reveals normal SC myelination and confirms

1186 the reorganization of the endoneurium by nascent MFs (arrowheads). (H) qPCR of P5 controls and

1187 Dhh KOs shows Dhh is not detectable and Gli1 expression is reduced to $\sim 40 \%$ of control in Dhh

1188 nulls. Dhh: Ctrl $(1.00 \pm 0.015)$ vs KO (N.D.); Gli1: Ctrl $(1.00 \pm 0.027)$ vs KO $(0.42 \pm 0.082)$,

$1189 \mathrm{p}=.013$. (I) Cross section from P25 Dhh KO crossed to Gli $1^{n L a c Z /+}$ were stained as above showing

1190 similar results as observed at P5. (J) By EM, robust, multilayered MFs are visible throughout the

1191 endoneurium. (K) qPCR performed on P25 controls and Dhh KOs shows that Dhh is not

1192 detectable, but Gli1 levels are now at or above control levels. Dhh: Ctrl $(1.00 \pm 0.015)$ vs KO

1193 (N.D.); Gli1: Ctrl (1.00 \pm 0.067$)$ vs KO (1.42 \pm 0.20$), p=.16$. Values shown represent mean $\pm \mathrm{SEM}$

1194 analyzed using unpaired t-test with Welch's correction based on $n=3$ biological replicates per 
genotype; ${ }^{*} \mathrm{p}<.05,{ }^{* *} \mathrm{p}<.01, \mathrm{~ns}=$ not significant, N.D.=not detected. Scale bars: (A, C, F, I) $50 \mu \mathrm{m}$, (B, D, G, J) $2 \mu \mathrm{m}$.

Figure 3: Gli1 controls minifascicle formation but not nerve sheath development

(A) Cross section of a fate mapped Glil het sciatic nerve reveals numerous tdT-positive endoneurial cells. Inset shows the normal EM morphology of a Gli1 het EF (arrowhead). (B) Cross section of a fate mapped Gli1 null sciatic nerve shows reorganization of the endoneurium into MFs by tdT-positive cells. Inset shows an EM of a MF boundary, comprised of thin, elongated cellular processes. (C) Fate mapping (red) overlaps almost entirely with PDGFR $\alpha$ staining (green), in a the epineurium (E) and perineurium (P) in Glil hets and nulls. Inset shows high power image of concentric layers of PNG. (F) EM cross section of age-matched Dhh null reveals minimal epineurium and a limited perineurium consisting of a few, uncompacted layers. (G) A local injection of Evans Blue-Albumin (EBA, red) was stopped by the perineurial barrier in Gli1 hets (arrow). (H) In Gli1 nulls, most EBA was retained within the perineurium (arrow); small amounts tracked between MF boundaries (inset, arrowhead) which anastomose with the perineurium and allow for dye entry. EBA does not enter the endoneurial compartment. (I) Gli1 null nerves stained consistent with their intact barrier function. Scale bars: (A-B main) $100 \mu \mathrm{m},(\mathrm{A}-\mathrm{B}$ inset) $5 \mu \mathrm{m},(\mathrm{C})$ $100 \mu \mathrm{m}$, (D-F main) $2 \mu \mathrm{m}$, (D-F inset) $0.5 \mu \mathrm{m},(\mathrm{G}-\mathrm{H}) 100 \mu \mathrm{m}$, (I) $50 \mu \mathrm{m}$. 
1217 (A, B) Pregnant Gli1 het and null dams were treated with tamoxifen to fate map embryos of in

1218 utero at E13. Nerves were harvested at P30, sectioned longitudinally and stained for GFP (green),

1219 used as a fate mapping reporter, and for S100ß, a marker of SCs (blue). (A) Gli1 hets show fate

1220 mapping of EFs (arrowhead) and PNG (arrow), but not SCs. (B) Gli1 nulls show fate mapping of

1221 MF-forming cells (arrowhead) and PNG (arrow), but not SCs. (C-H) EM cross sections from Gli1

1222 het and null sciatic nerves from the indicated postnatal times are shown, with endoneurial cells

1223 and MFs outlined in red lines. Insets showing fields at higher magnification; individual

1224 endoneurial cells are pseudocolored red. (C, D) At P1, little to no myelin is present. Immature EFs

1225 in both hets and nulls extend long processes between axon families; many radiate outward from

1226 endoneurial blood vessels (insets, stars). (E, F) At P10, robust myelination is observed. EFs in Gli1

1227 hets have retracted their processes and dispersed throughout the endoneurium whereas EFs in Gli1

1228 nulls lengthen processes and begin to wrap around groups of SCs. $(\mathrm{G}, \mathrm{H})$ In adult nerves,

1229 myelination is complete. In Glil hets, EFs are fusiform with short irregular processes whereas in

1230 Gli1 nulls the endoneurium is fasciculated by layers of elongated cells. EFs do not form a basal

1231 lamina ( $\mathrm{G}$ inset, white arrow), however a basal lamina is formed by fasciculating cells ( $\mathrm{H}$ inset,

1232 white arrow) and all Schwann cells (G-H insets, yellow arrows). Scale bars: (A-B) $50 \mu \mathrm{m},(\mathrm{C}-\mathrm{H}$,

1233 main) $20 \mu \mathrm{m},(\mathrm{C}-\mathrm{H}$, insets) $2 \mu \mathrm{m},(\mathrm{G}-\mathrm{H}$, double insets) $200 \mathrm{~nm}$.

1234

1235 Figure 5: Loss of Gli1 increases endoneurial fibroblast proliferation in vivo

1236 (A, B) Cross sections of P5 Gli1 ${ }^{\mathrm{LacZ} /+}$ het and Gli1 ${ }^{\mathrm{CE} / \mathrm{LacZ}}$ null sciatic nerves were stained for $\beta \mathrm{Gal}$

1237 (red), Sox10 (SCs, green), and EdU (blue) to mark proliferating cells. Insets: Dividing Gli1 cells

1238 (magenta) are found in the endoneurium (E, arrows) and perineurium ( $\mathrm{P}$, arrowheads). Dividing

1239 SCs are cyan (stars). (C) Gli1- $\beta$ Gal-positive cells were increased in Gli1 nulls vs hets at all 
1240 postnatal timepoints. P1: Het $(78.7 \pm 7.7)$ vs Null $(118.4 \pm 9.2), p=0.029 ;$ P5: Het $(113.7 \pm 17.0)$

1241 vs Null $(196.9 \pm 23.0), \mathrm{p}=0.044 ;$ P10: Het $(106.6 \pm 13.7)$ vs Null $(225.8 \pm 10.7), \mathrm{p}=0.0024 ; \mathrm{P} 15$ :

1242 Het $(111.2 \pm 7.1)$ vs Null $(219.7 \pm 21.1), \mathrm{p}=0.0082$; Adult: Het $(112.0 \pm 16.6)$ vs Null $(231.0 \pm$

1243 19.1), $\mathrm{p}=0.0093$. (D) Proliferation of Gli1- $\beta$ Gal-positive cells as measured by EdU incorporation

1244 is increased in endoneurial but not perineurial cells in Gli1 nulls vs. Glil hets at the times indicated.

1245 Endoneurium: P1: Het $(2.5 \pm 0.42)$ vs Null $(6.6 \pm 1.0), \mathrm{p}=0.041 ;$ P5: Het $(2.5 \pm 0.70)$ vs Null (7.4

$1246 \pm 1.4), \mathrm{p}=0.053 ;$ P10: Het $(1.2 \pm 0.72)$ vs Null $(4.0 \pm 0.44), \mathrm{p}=0.038 ;$ Perineurium: P1: Het (6.3

$1247 \pm 0.68)$ vs Null $(4.9 \pm 0.74), p=0.25 ;$ P5: Het $(3.7 \pm 1.2)$ vs Null $(3.8 \pm 0.61), p=0.94 ;$ P10: Het

$1248(1.6 \pm 0.41)$ vs Null $(1.9 \pm 0.32), \mathrm{p}=0.56$. (E, F) EM of adult Gli1 het and null sciatic nerves

1249 highlighting "free" EFs (arrowheads), i.e., isolated from any other EF/PNG cell processes. MFs

1250 are visible in Gli1 nulls (arrow). (G) Free EFs are reduced in the Gli1 nulls (1.22 \pm 0.11$)$ vs Gli1

1251 het $(3.33 \pm 0.51)$ per field, $\mathrm{p}=0.0479$. Values shown represent mean $\pm \mathrm{SEM}$ analyzed using 1252 unpaired t-test with Welch's correction based on $\mathrm{n}=3$ biological replicates per genotype; $* \mathrm{p}<.05$, $1253 * * \mathrm{p}<.01$. Scale bars: (A-B, main) $50 \mu \mathrm{m},(\mathrm{A}-\mathrm{B}$, insets) $5 \mu \mathrm{m},(\mathrm{E}-\mathrm{F}) 5 \mu \mathrm{m}$.

1254

Figure 6: Gli1 loss drives EF/PNG proliferation in vitro

1256 (A-C) Gli1-fate mapped cells, established from sciatic nerve explants of Gli1 het and nulls, were 1257 cultured for $48 \mathrm{hr}$ in either control media or media containing $5 \mu \mathrm{M}$ GANT61, an inhibitor of Gli1 1258 and Gli2 activity. Cells were fixed and stained with antibodies to the tdT reporter (red), Ki67 1259 (green), and Hoechst (nuclei, blue). Dividing EF/PNG are red with cyan nuclei (arrows). (D) The 1260 total number of tdT-positive cells per field was increased in Gli1 nulls $(34.5 \pm 2.75)$ and in Gli1 1261 hets + GANT61 (36.17 \pm 1.36$)$ compared to Gli1 het controls (19.33 \pm 1.69$) ;$ Het vs Het+GANT61 $1262 \mathrm{p}=0.0038$, Het vs Null $\mathrm{p}=0.043$, Het + GANT61 vs Null $\mathrm{p}=0.92$. (E) The proliferation rate, as 
assessed by Ki67 staining, was increased in Gli1 nulls $(29.91 \pm 1.57)$ and Gli1 hets + GANT61

$1264(24.68 \pm 1.88)$ vs Gli1 het controls $(10.35 \pm 1.70)$ cultures; Het vs Het+GANT61 $p=0.012$, Het vs

1265 Null $p=0.0027$, Het + GANT61 vs Null $p=0.23$. Values shown represent mean \pm SEM analyzed

1266 using Welch's ANOVA test with Dunnett's T3 multiple comparisons test based on n=10 fields

1267 across multiple coverslips per condition and $n=3$ biological replicates per genotype (prepared from

1268 separate nerves); $* \mathrm{p}<.05, * * \mathrm{p}<.01$, ns $=$ not significant. (F) $\mathrm{qPCR}$ performed on cultured cells

1269 confirms suppression of Gli1 by GANT61 treatment. Het $(1.02 \pm 0.16)$ vs Het+GANT61 $(0.66 \pm$

1270 0.11), $\mathrm{p}=.029$; Gli1 null (N.D.). Values shown represent mean \pm SEM analyzed using paired t-test

1271 based on $\mathrm{n}=3$ biological replicates per genotype; $* \mathrm{p}<.05$, N.D. $=$ not detected. Scale bars: (A-C)

$1272100 \mu \mathrm{m}$.

1274 Figure 7: Minifascicles in Gli1 and Dhh nulls express only an EF marker at P5 but express

\section{both EF and PNG markers in adult nerves}

1276 Cross sections of P5 and adult control (A, D, G, J), Gli1 null (B, E, H, K) and Dhh null (C, F, I, L) nerves show staining for PDGFR $\alpha$ (red) and either CD34 (A-C, G-I) or Glut-1 (D-F, J-L), (both

1278 green). Insets are higher magnifications of the boxed area showing separated channels. (A) P5

1279 control nerve inset shows labeling of an EF (arrowhead) and an EC, which expresses CD34 but

1280 not PDGFR $\alpha$ (star). Epineurial fibroblasts also express CD34 (arrow). In P5 Gli1 null (B) and Dhh

1281 null (C) nerves, nascent MFs are extensively labeled by CD34 (insets, arrowhead). (D) P5 control

1282 nerves shows Glut-1 is expressed by PNG (arrow) but not EFs (inset, arrowhead). ECs also express

1283 Glut-1 but not PDGFRa (inset, star). In P5 Gli1 null (E) and Dhh null (F) nerves, nascent MFs are

1284 not labeled by Glut-1 (insets, arrowhead). The Glut-1 positive perineurium present in Gli1 nulls

1285 (E, arrowhead) is absent from in Dhh nulls. (G) Adult control nerve stained shows labeling of EFs 
1286 (inset, arrowhead), ECs (inset, star), and epineurial fibroblasts (arrow). In both adult Gli1 null (H)

1287 and Dhh null (I) nerves, mature MFs continue to express CD34 (insets, arrowhead). (J) Adult

1288 control nerve for Glut-1 shows labeling of PNG (arrow) and ECs (inset, star), but not EFs (inset,

1289 arrowhead). In adult Gli1 null (K) and Dhh null (L) nerves, mature MFs express high levels of

1290 Glut-1. Gli1 nulls also have a robust Glut1-positive perineurium that surrounds the MFs (K, arrow)

1291 which is largely absent in the Dhh nulls. Scale bars: (A-F, main) $50 \mu \mathrm{m},(\mathrm{A}-\mathrm{F}$, insets) $4 \mu \mathrm{m},(\mathrm{G}-\mathrm{L}$, 1292 main) $100 \mu \mathrm{m},(\mathrm{G}-\mathrm{L}$, insets) $20 \mu \mathrm{m}$.

Figure 8: Gli1 expression controls peripheral nerve vascularization

1295 (A, B) Sciatic nerve sections from adult fate mapped Gli1 hets and nulls (tdT, red) were stained

1296 for the EC marker CD31 (green). Vessels are surrounded by Gli1-positive cells in both hets and

1297 nulls. (C) Density of CD31+ vessels is significantly increased in adult Gli1 nulls (36.22 \pm 2.50$)$ vs

1298 hets $(20.78 \pm 2.21), \mathrm{p}=0.010$. (D) Nerve cross sections from Gli1 het or null mice at the indicated

1299 postnatal timepoints were stained for tdT and CD31. Blood vessels are closely associated with tdT-

1300 positive cells starting at P1 in both genotypes; MFs surround endoneurial vessels in Gli1 nulls. (E)

1301 Quantification shows vasculature is significantly increased in Gli1 nulls starting at P1 and 1302 persisting into adulthood. P1: Het (13.22 \pm 1.42$)$ vs Null (24.22 \pm 2.41$), p=0.025 ;$ P5: Het (15.63

$1303 \pm 1.71)$ vs Null $(32.22 \pm 2.00), \mathrm{p}=0.0035 ;$ P10: Het $(18.67 \pm 1.39)$ vs Null $(33.00 \pm 2.34), p=0.011$

1304 (F, G) Nerve cross sections from Glil het and null mice injected intravenously with Evans Blue 1305 Albumin (EBA, red) shows the dye is contained within endoneurial vessels in both Gli1 hets and 1306 nulls (arrowheads). Dye also diffuses along MFs in Gli1 nulls (arrow) but does not penetrate into 1307 the endoneurium. (H, I) Nerve sections from Gli1 het and null fate mapped mice were crossed with 1308 the $\mathrm{CX} 3 \mathrm{CR} 1^{\mathrm{EGFP} /+}$ reporter line to label macrophages with GFP. (J) The density of macrophages 
was not significantly altered in Gli1 nulls $(30.44 \pm 3.25)$ vs hets $(23.33 \pm 2.99), p=0.18$. Values

shown represent mean \pm SEM analyzed using unpaired t-test with Welch's correction based on

main) $100 \mu \mathrm{m},(\mathrm{A}, \mathrm{B}$ : insets) $5 \mu \mathrm{m}$, (D) $50 \mu \mathrm{m}$, (F-I) $100 \mu \mathrm{m}$.

1315 (A, B) High magnification EMs reveal a decrease in collagen fibrils (arrowheads) in the Gli1 nulls

nulls $(60.67 \pm 11.05)$ compared to hets $(231.7 \pm 37.55), \mathrm{p}=0.036$. (D, E) Gli1 het and null sciatic

1321 Staining intensity is decreased in the endoneurium of Gli1 nulls although MF are moderately

1322 stained (arrow). (H) Transcript levels for several key collagen genes were determined by qPCR

1323 and show significant decreases for the 3 main fibril-forming collagen genes expressed in the 1324 endoneurium. COL1A1: Het $(1.00 \pm 0.10)$ vs Null $(0.59 \pm 0.05), \mathrm{p}=0.042$; COL2A1: Het $(1.00 \pm$

1325 0.07) vs Null $(0.72 \pm 0.033), \mathrm{p}=0.035 ;$ COL3A1: Het $(1.00 \pm 0.06)$ vs Null $(0.74 \pm 0.05), p=0.033$.

1326 Values shown represent mean \pm SEM analyzed using unpaired t-test with Welch's correction based

1327 on $n=10$ fields per replicate $(C)$ and $n=3$ biological replicates per genotype $(C, H) ; * p<.05$. Scale

1328 bars: (A, B) $0.5 \mu \mathrm{m},(\mathrm{D}, \mathrm{E}$, main) $10 \mu \mathrm{m},(\mathrm{D}, \mathrm{E}$, insets) $2 \mu \mathrm{m}$, (F-G) $10 \mu \mathrm{m}$. 
1331 (A, B) EM cross sections demonstrate increased spacing between axon-SC units in nerves of Gli1

1332 nulls vs hets. (C) Calculation of axon density reveals a significant decrease in Gli1 nulls $(0.023 \pm$

$13330.0019)$ compared to hets $(0.034 \pm 0.0031), \mathrm{p}=0.0424$. (D) Total axon numbers were similar in

1334 Gli1 het $(4763 \pm 85.38)$ and null nerves $(4564 \pm 108.9), p=0.98$. (E) Average g-ratios of myelinated

1335 fibers were calculated within the indicated diameter ranges and indicate a modest

1336 hypermyelination of small and medium size axons in Gli1 nulls. 1-3 $\mu \mathrm{m}$ : Het $(0.63 \pm 0.004)$ vs Null

$1337(0.61 \pm 0.003), \mathrm{p}=0.003,3-5 \mu \mathrm{m}$ : Het $(0.66 \pm 0.003)$ vs Null $(0.63 \pm 0.003), \mathrm{p}<.0001,5-7 \mu \mathrm{m}:$ Het

$1338(0.67 \pm 0.004)$ vs Null $(0.65 \pm 0.004), p=0.0001,7+\mu m: \operatorname{Het}(0.72 \pm 0.003)$ vs Null $(0.71 \pm 0.003)$

$1339 \mathrm{p}=0.081$. (F) Scatterplot of axon diameter vs g-ratio for single myelinated fibers in adult Gli1 hets

1340 and nulls. Distributions are largely overlapping with a slight shift towards lower g-ratios for

1341 smaller-diameter axons for Gli1 nulls vs hets. Lines of best fit: Gli1 het $(y=0.015 x+0.60)$ vs Gli1

1342 null $(y=0.017 x+0.56)$. (G) A shift from larger to smaller axon diameters is observed in Gli1 nulls.

$1343 \mathrm{p}=0.63($ Total vs $0-1 \mu \mathrm{m}), \mathrm{p}=0.12($ Total vs $1-2 \mu \mathrm{m}), \mathrm{p}=0.31($ Total vs $2-3 \mu \mathrm{m}), \mathrm{p}=0.042$ (Total vs 3-

$13444 \mu \mathrm{m}), \mathrm{p}=0.18($ Total vs $4-5 \mu \mathrm{m}), \mathrm{p}=0.0002($ Total vs $5-6 \mu \mathrm{m}), \mathrm{p}=0.13($ Total vs $6-7 \mu \mathrm{m}), \mathrm{p}=0.99($ Total

1345 vs 7+ $\mu \mathrm{m})$. (H, I) Remak bundles containing as few as 1-2 axons (I, arrowheads) were frequently

1346 observed in Gli1 nulls but not in hets. (J) Remak bundles were binned by number of axons per bundle,

1347 showing a shift towards lower axon:SC ratios (i.e., 1:1 and 1:2) in Gli1 nulls. (C, D) Values shown

1348 represent mean \pm SEM analyzed using unpaired t-test with Welch's correction based on $n=3$

1349 biological replicates per genotype; ${ }^{*} \mathrm{p}<.05$, $n s=$ not significant. (E-G) $>1000$ axons across $n=3$

1350 biological replicates per genotype were traced, (E) Axons were binned by diameter and average g-

1351 ratio was analyzed by t-test as above, $(\mathrm{G})$ Axon diameters were binned as a percentage of total

1352 axons measured and analyzed by Fisher's exact test; ${ }^{*} \mathrm{p}<.05,{ }^{* *} \mathrm{p}<.01,{ }^{* * *} \mathrm{p}<.001 .(\mathrm{J})>150$ Remak 
1353 bundles per genotype were analyzed, number of observations was insufficient for Fisher's testing.

1354 Scale bars: (A, B) $5 \mu \mathrm{m},(\mathrm{H}, \mathrm{I}) 1 \mu \mathrm{m}$.

1356 Figure 11: Inducible knockout of Gli1 results in minifascicle formation in adult nerves

1357 (A) Schematic of Gli1 ${ }^{\mathrm{CE}}$ and Gli1 ${ }^{\mathrm{Fl}}$ alleles. LoxP sites flank exons 5-9 of the Gli1 coding sequence.

1358 After tamoxifen administration to Gli1 ${ }^{\mathrm{CE} / \mathrm{Fl}}$ mice, Cre-mediated excision of this sequence results in 1359 Gli1 inducible knockout (iKO). Gli1 ${ }^{\mathrm{CE}}$ also drives expression of the Ai9 reporter. (B) Tamoxifen was 1360 given on alternating days for 4 injections and analyses were performed at 5 and 8 weeks. (C) qPCR for 1361 Gli1 transcripts reveals equivalent levels in Gli1 ${ }^{\mathrm{CE} / \mathrm{Fl}}$ mice prior to tamoxifen administration and 1362 Gli1 ${ }^{\mathrm{CE} /+}$ hets at 5 and 8 weeks, confirming that insertion of the LoxP sites did not interfere with 1363 endogenous Glil transcription. In Glil iKO mice at both 5 and 8 weeks, Glil transcript levels are 1364 reduced to $1-2 \%$ of littermate controls. Gli1 ${ }^{\mathrm{CE} / \mathrm{Fl}}$ No TMX $(1.00 \pm 0.11)$, Gli1 Het 5 wk $(1.13$ $1365 \pm 0.11)$, Gli1 iKO 5 wk (0.017 \pm 0.003), Gli1 Het 8 wk (0.95 \pm 0.04$)$, Gli1 iKO 8 wk (0.027 \pm 0.007$)$ 1366 Het 5 wk vs iKO 5 wk p=.03, Het 8 wk vs iKO 8 wk p=.008. (D) Gli1 het and iKO nerves at 5 weeks 1367 post-tamoxifen shows fate mapped cells forming nascent MFs. (E) By 8 weeks post-tamoxifen, Gli1 1368 iKO nerves contain dense MFs, similar to Gli1 constitutive nulls. (F) Examination at an early timepoint 1369 (4 weeks) shows MFs forming both at the periphery (inset i) as well as in the interior (inset ii) of the 1370 nerve. Values shown in panel C represent mean \pm SEM analyzed using Welch’s ANOVA test with 1371 Dunnett's T3 multiple comparisons test based on $\mathrm{n}=3$ biological replicates per genotype; ${ }^{*} \mathrm{p}<.05$, $1372 * * \mathrm{p}<.01, \mathrm{~ns}=$ not significant. Scale bars: (D-E) $100 \mu \mathrm{m}$, (F, main) $50 \mu \mathrm{m}$, (F, insets) $25 \mu \mathrm{m}$. 
1375 (A) Diagram of Gli1 ${ }^{\mathrm{CE}}$ and ROSA ${ }^{\mathrm{Gli} 1}$ alleles. LoxP sites flank a transcriptional stop site upstream of 1376 the full Gli1 coding sequence. After tamoxifen administration to Gli1 ${ }^{\mathrm{CE}}$; ROSA ${ }^{\mathrm{Gli}}$ mice, Cre-mediated 1377 excision of the stop site results in Glil overexpressors (OE) which constitutively express Gli1 under 1378 the ROSA26 promoter. Gli1 ${ }^{\mathrm{CE}}$ also drives expression of the RCE (GFP) reporter. (B) Tamoxifen was 1379 given on alternating days for 4 injections and analysis was performed at 6 weeks. (C) qPCR was 1380 performed on sciatic nerves of adult Gli1 het $\operatorname{ctrl}\left(G l i 1^{C E /+} ; R C E\right)$, null $\operatorname{ctrl}\left(G l i 1^{C E / C E} ; R C E\right)$, het $1381 \mathrm{OE}\left(\mathrm{Gli}^{C E /+} ; R C E /\right.$ RGli1), and null OE (Gli1 $\left.{ }^{C E / C E} ; R C E / R G l i 1\right)$ mice. Gli1 transcript levels in Het 1382 OE are increased 81\% above Gli1 het controls. Gli1 null controls express virtually no Gli1, while 1383 Gli1 null OE have transcript levels $91 \%$ of het controls. Het Ctrl (1.00 \pm 0.029$)$, Het OE (1.88 \pm 1384 0.087), Null Ctrl (0.022 \pm 0.014), Null OE (0.91 \pm 0.072); Het Ctrl vs Null Ctrl p=.0003, Het Ctrl 1385 vs Het OE $p=0.033$, Null ctrl vs Null OE $p=0.02$, Null ctrl vs Het OE $p=0.0068$. (D-E) GFP staining 1386 of fate mapped cells in the indicated genotypes shows no evident morphological differences 1387 between het ctrl and het OE (D) or between null ctrl and null OE (E). Isolated EF are labeled in all 1388 Gli1 hets (D, arrowheads) and MFs are labeled in Gli1 nulls (E, arrowheads). Values shown in 1389 panel C represent mean \pm SEM analyzed using Welch's ANOVA test with Dunnett's T3 multiple 1390 comparisons test based on $\mathrm{n}=3$ biological replicates per genotype; $* \mathrm{p}<.05, * * \mathrm{p}<.01, * * * \mathrm{p}<.001$, 1391 ns=not significant. Scale bars: $(B-E) 100 \mu \mathrm{m}$. 


\section{Extended Data}

Extended Data Figure 1: Gli2 is expressed in Gli1 fate mapped cells in the PNS

(A, B) $G l i 1^{C E /+} ; t d T$ mice were crossed to $G l i 2^{\text {LLacZ/+ }}$ mice and fate mapped to label Gli1-expressing cells. Cross sections of sciatic nerves were stained for Gli1:tdT and $\beta$ Gal (Gli2-positive cells, green). (C) The majority of endoneurial (arrowhead) and perineurial (arrow) Gli1 fate mapped cells co-expressed Gli2. Scale bars: (A-C) $100 \mu \mathrm{m}$.

Extended Data Figure 2: Expression of EF and PNG markers is regulated by cell density in vitro

1402 Fate mapped cells derived from sciatic nerve explants of Gli1 hets and nulls were plated at low density $1403\left(2,000\right.$ cells $\left./ \mathrm{cm}^{2}\right)$ or high density $\left(10,000\right.$ cells $\left./ \mathrm{cm}^{2}\right)$ in standard EF media and fixed after $48 \mathrm{hr}$.

1404 (A) Cultures stained for Gli1:tdT (red) show robust expression of CD34 (green) in fate mapped 1405 cells at low density and an apparent decrease in expression when cells were grown at higher 1406 density. This effect was present in both Gli1 het and null cultures. (B) Cultures stained for Gli1:tdT 1407 (red) show no detectable staining of Glut-1 (green) in fate mapped cells grown at low density. At 1408 high density, however, punctate expression of Glut-1 is observed at sites of cell-cell contact in 1409 both het and null cultures (see insets). Scale bars (A-B, main) $50 \mu \mathrm{m}$, (B, insets) $10 \mu \mathrm{m}$.

\section{Extended Data Video 1: 3D view of an adult Gli1 null sciatic nerve}

$1412(0: 00-0: 15)$ 3D reconstruction of adult Gli1 null sciatic nerves viewed in the XY plane and

1413 traversing along the z-axis. MF boundaries are traced in red, blood vessels (BV) are highlighted in

1414 blue. Frequent anastomoses of small MFs are seen with axons traversing between compartments.

1415 Note that BV are almost always embedded within MF structures. (0:15-0:30) 3D structures of MFs 
bioRxiv preprint doi: https://doi.org/10.1101/2021.09.14.460314; this version posted September 16, 2021. The copyright holder for this preprint (which was not certified by peer review) is the author/funder. All rights reserved. No reuse allowed without permission.

1416 are viewed from the side. Next, axons/SC units are revealed. Finally, the BV network is highlighted 1417 and shown to run within MFs. 


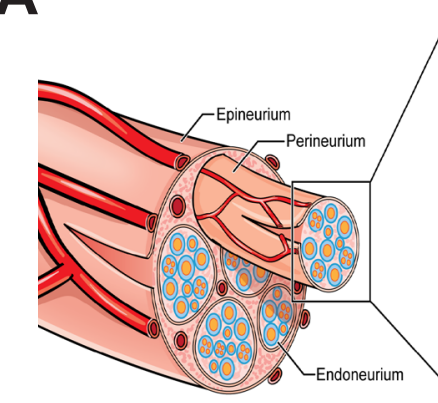

D

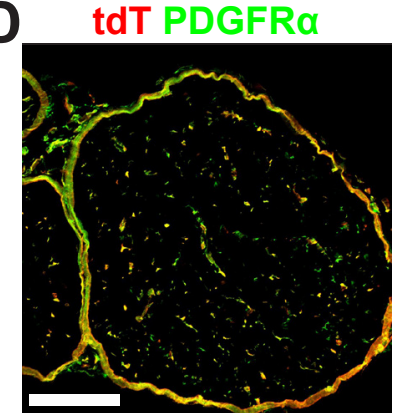

H

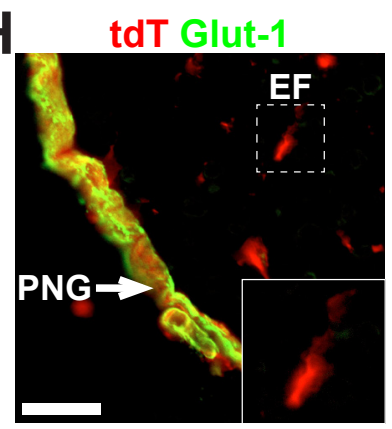

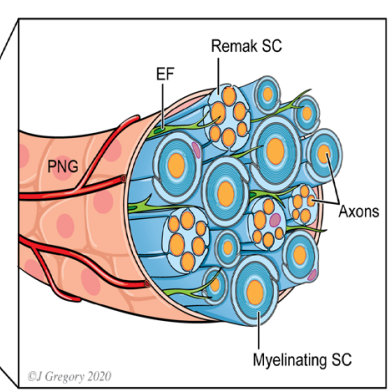

E tdT PDGFRa NG2
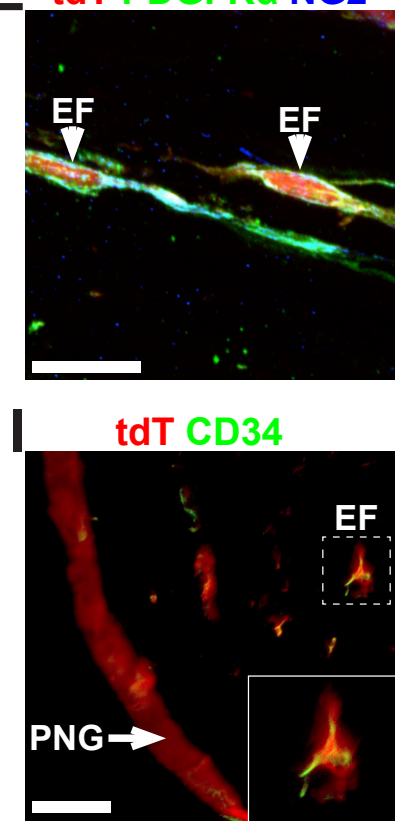

B

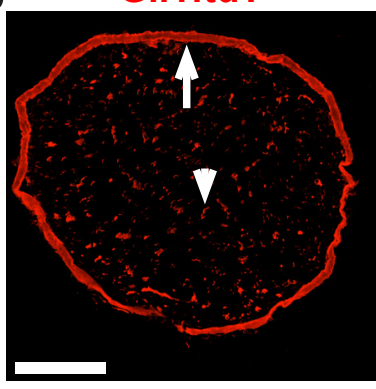

$F$

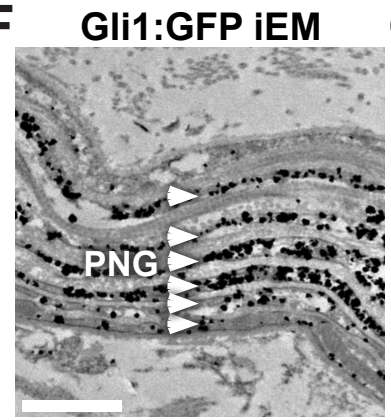

$\mathbf{J}$

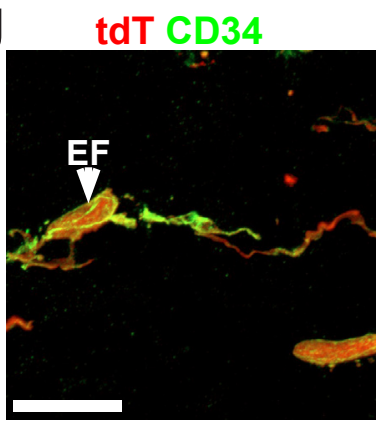

C tdT

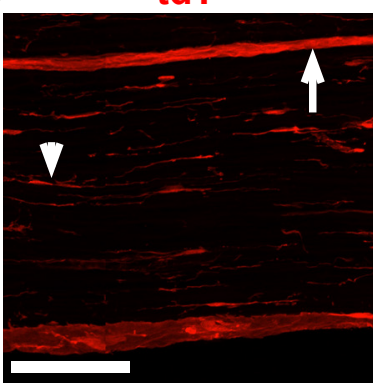

G

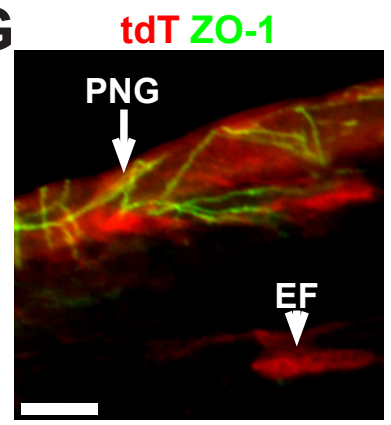

K tdT CD31 SMA

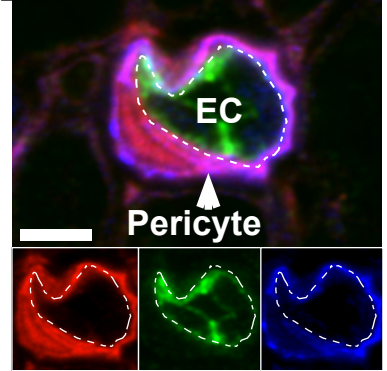

Figure 1: PNG, EF, and pericytes are Gli1-positive PNS cells 


\section{A Gli1 Het}

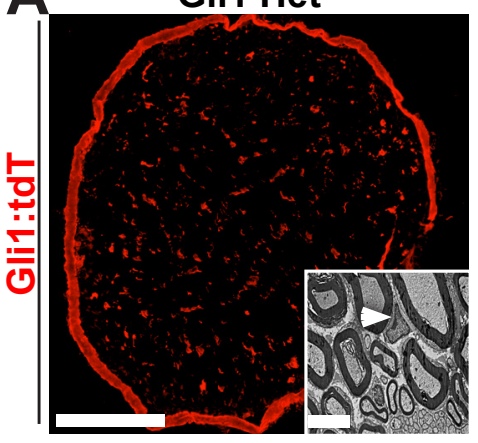

D

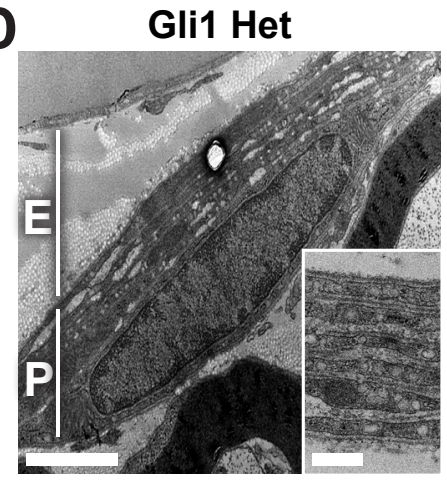

B

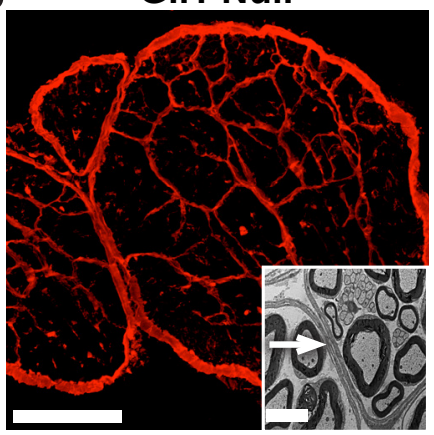

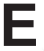

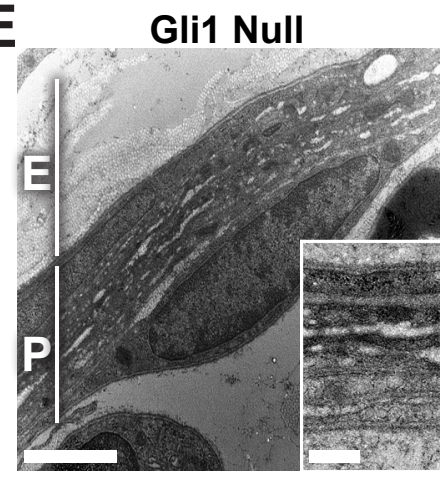

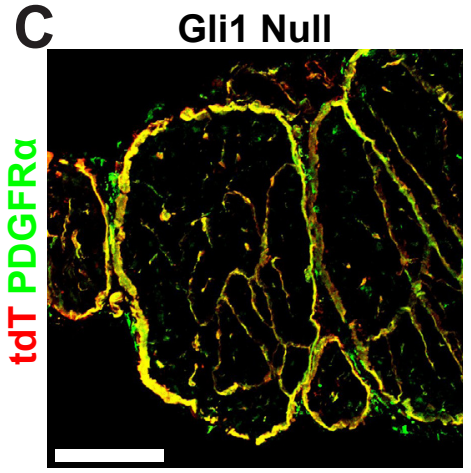

$\mathbf{F}$

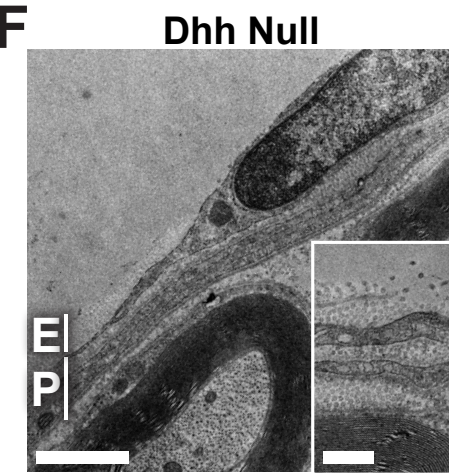

EBA

G

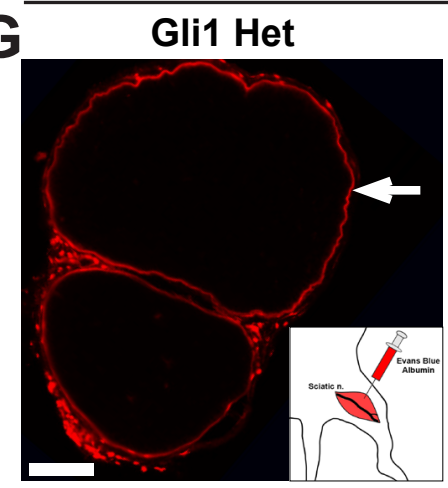

H

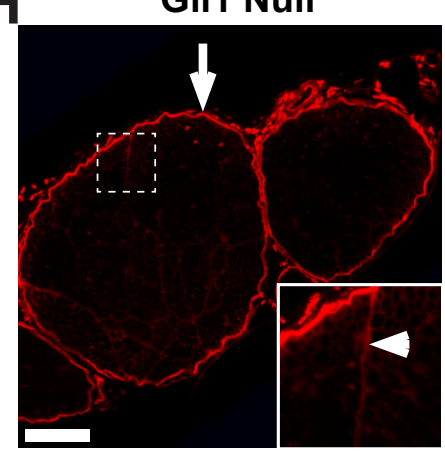

Gli1 Null

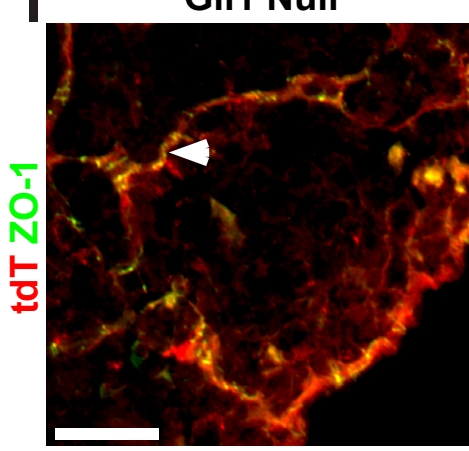

Figure 3: Gli1 controls minifascicle formation but not nerve sheath development 
A Gli1 Het

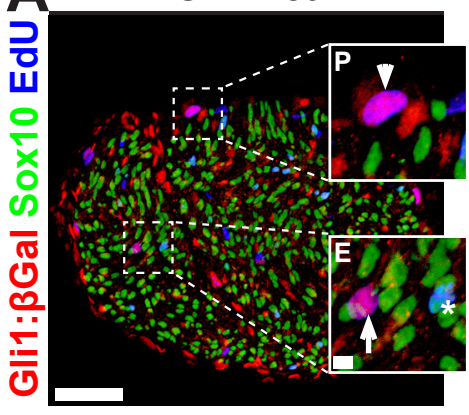

C
B Gli1 Null

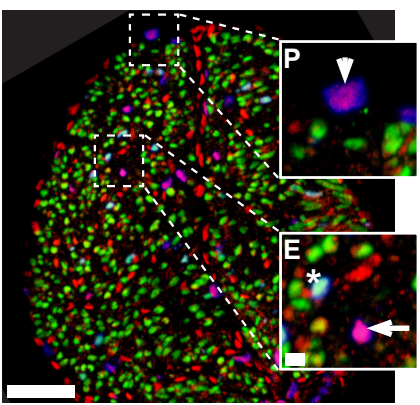

D
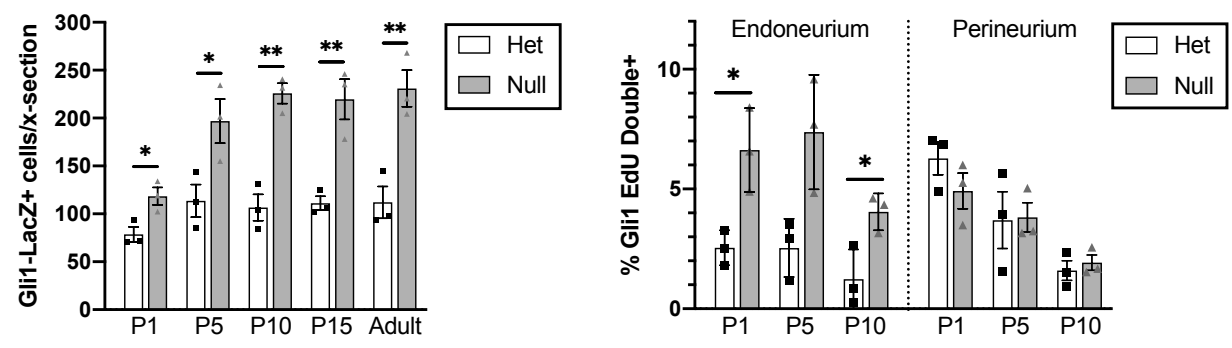

E

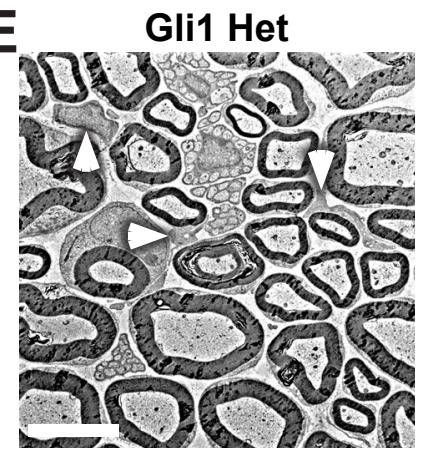

$\mathbf{F}$

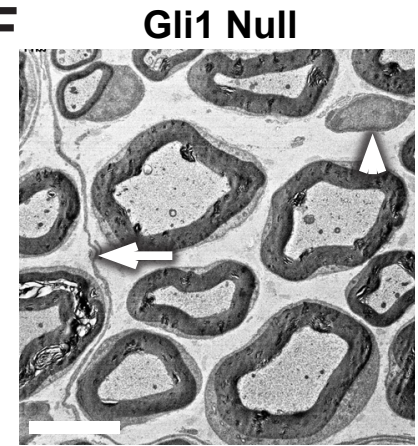

G

Figure 5: Loss of Gli1 increases endoneurial fibroblast proliferation in vivo

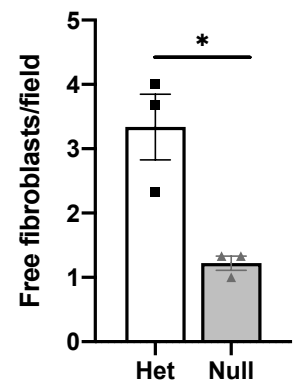


A Het

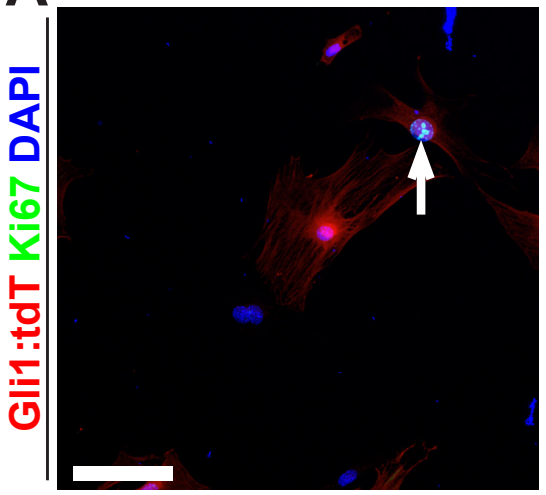

D

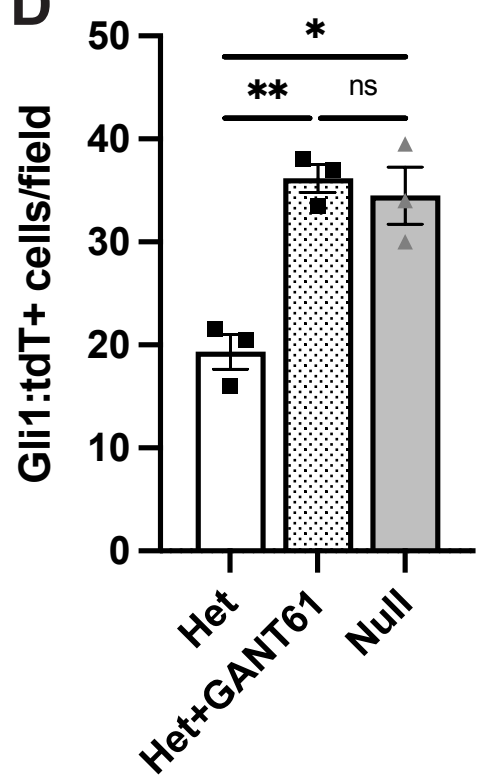

B

Het+GANT61

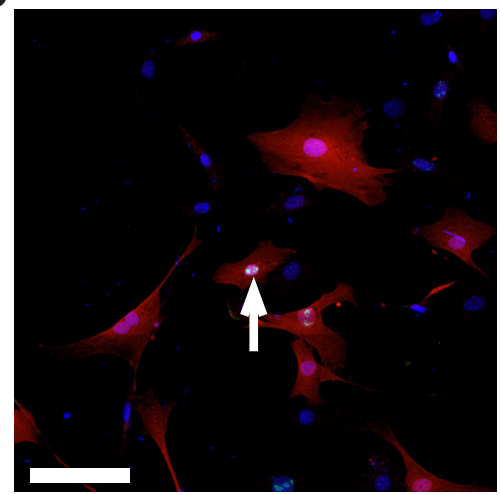

E

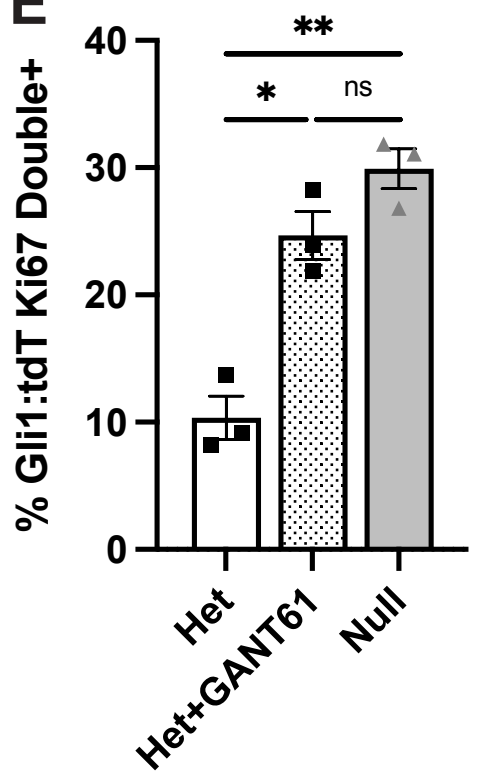

C Null

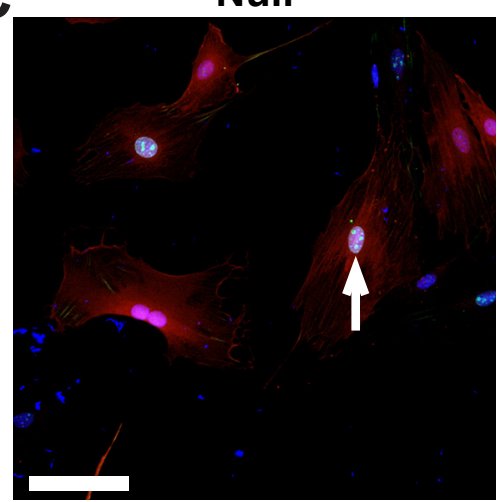

F

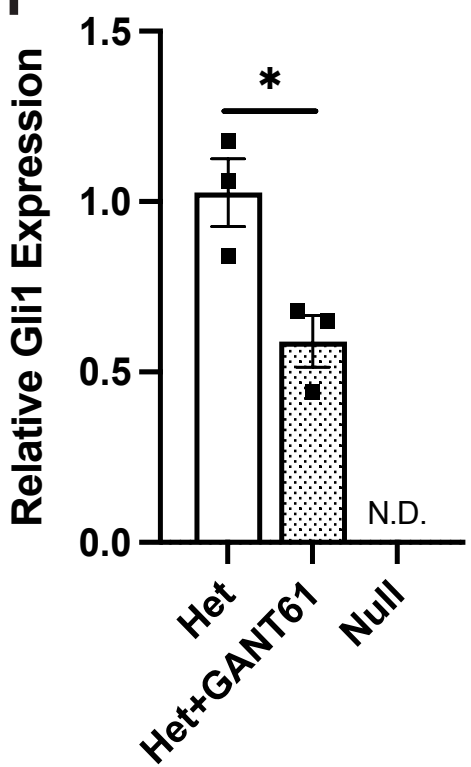

Figure 6: Gli1 loss drives EF/PNG proliferation in vitro 


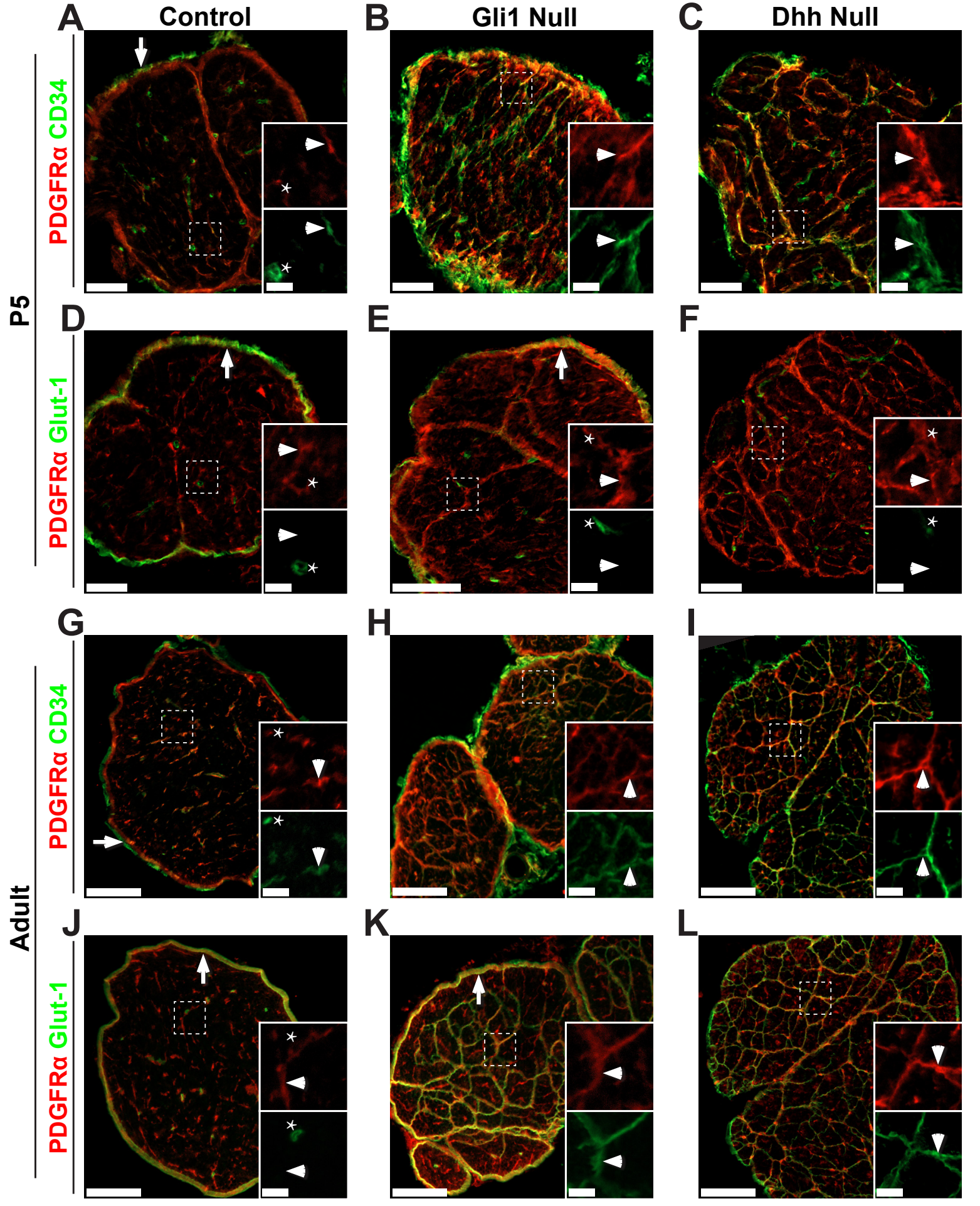

Figure 7: Minifascicles in Gli1 and Dhh nulls express only an EF marker at P5 but express both EF and PNG markers in adult nerves 


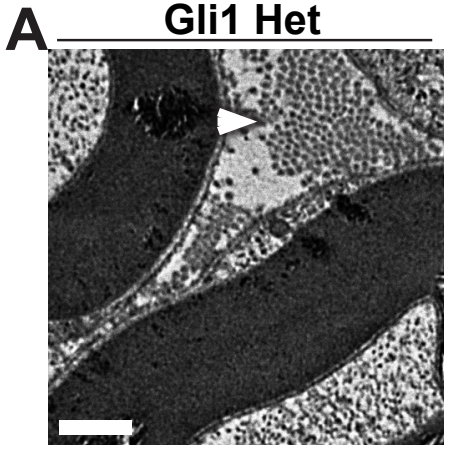

D

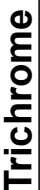

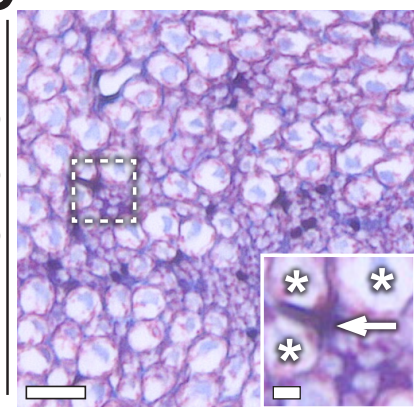

$\mathbf{F}$
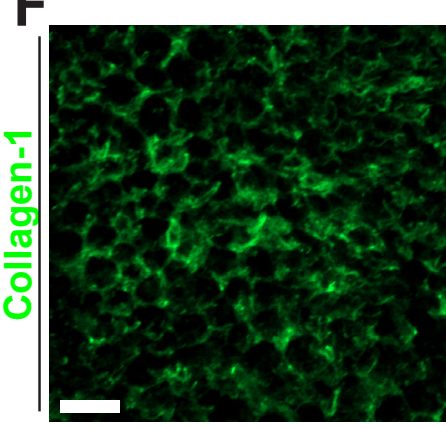

B

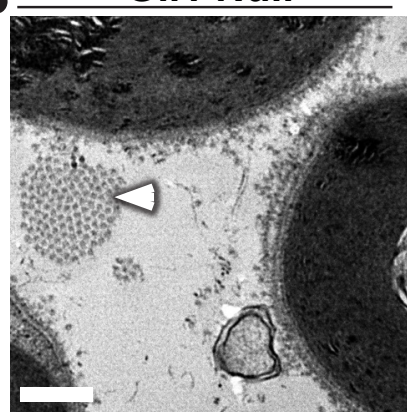

E

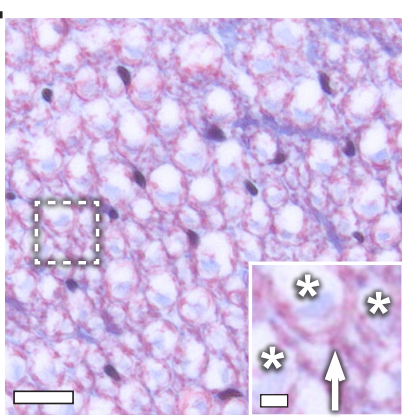

G

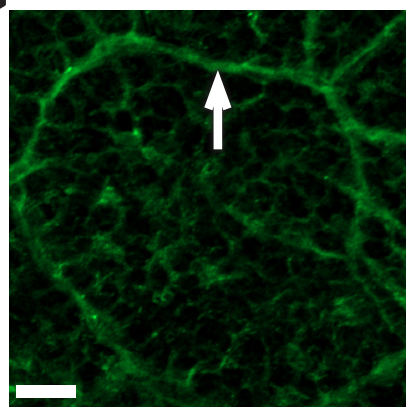

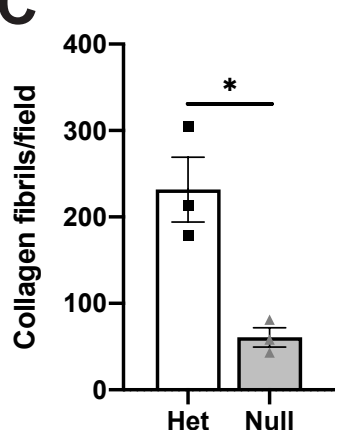

H

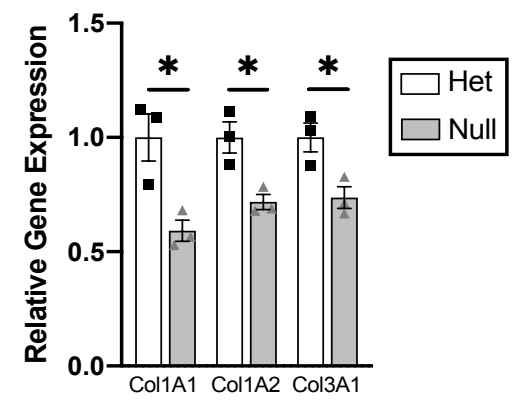

Figure 9: Gli1 expression controls peripheral nerve extracellular matrix 
A $\quad$ Gli1 Het

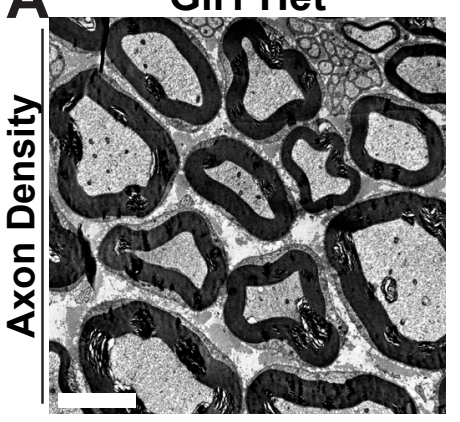

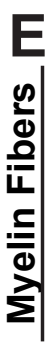

B

Gli1 Null

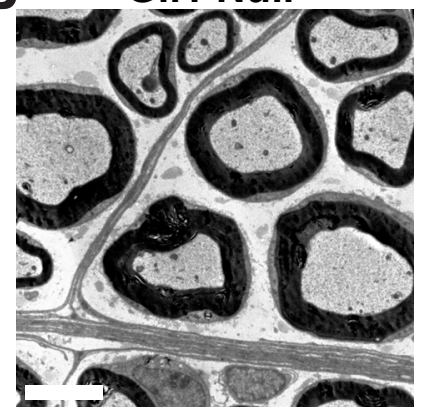

F
G
D

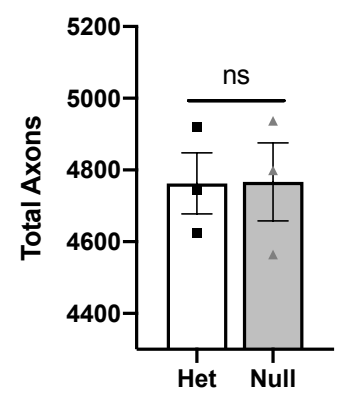

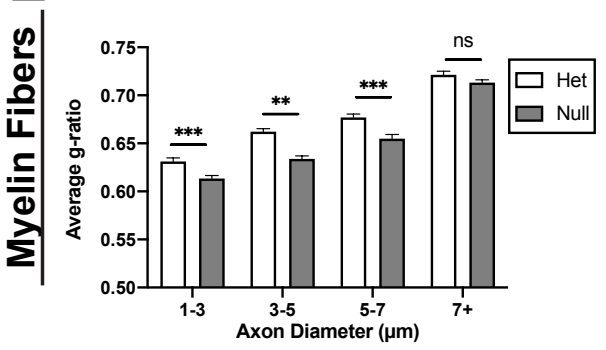

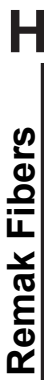

Gli1 Het

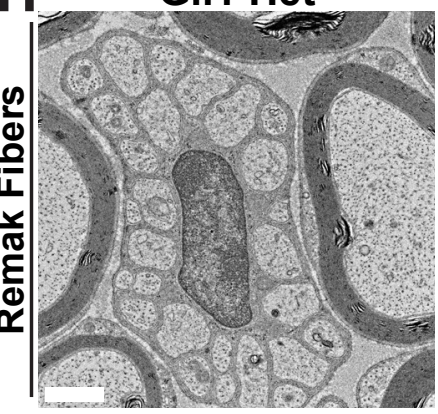

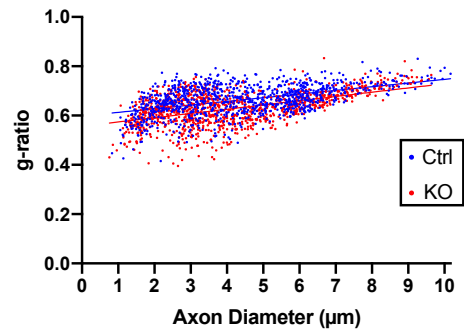
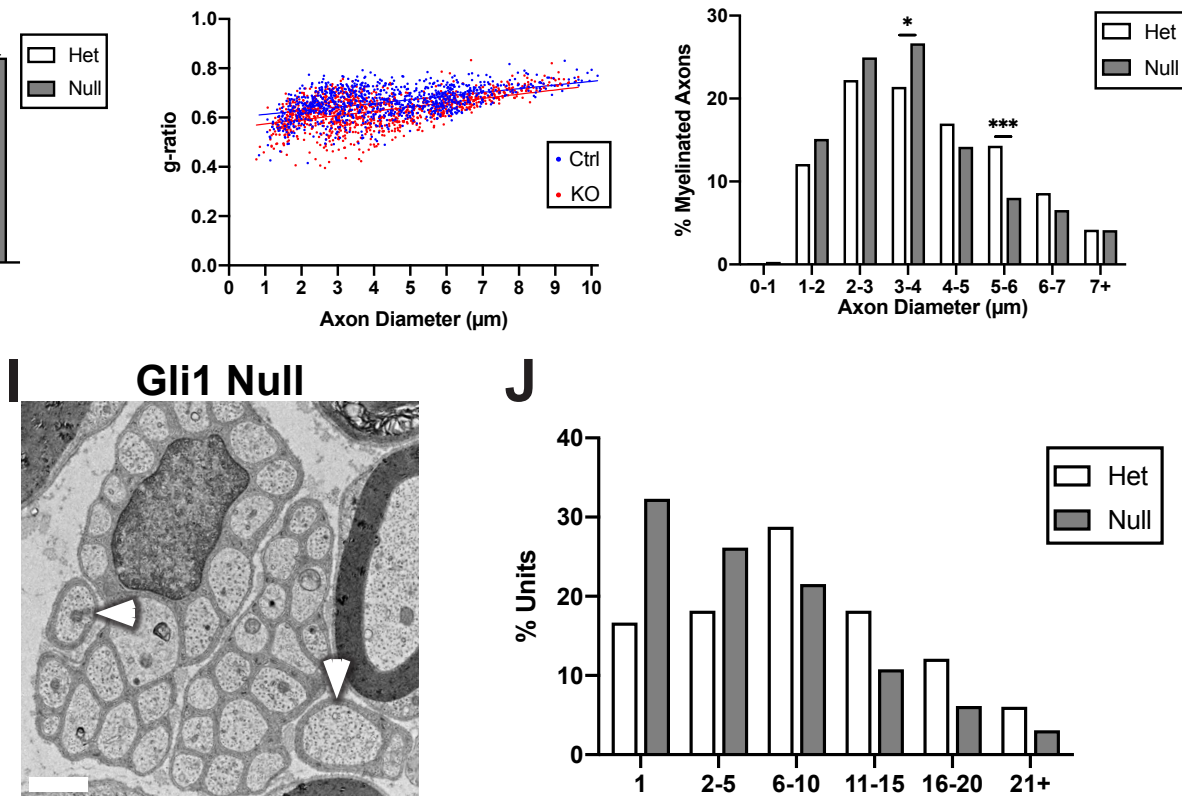

J

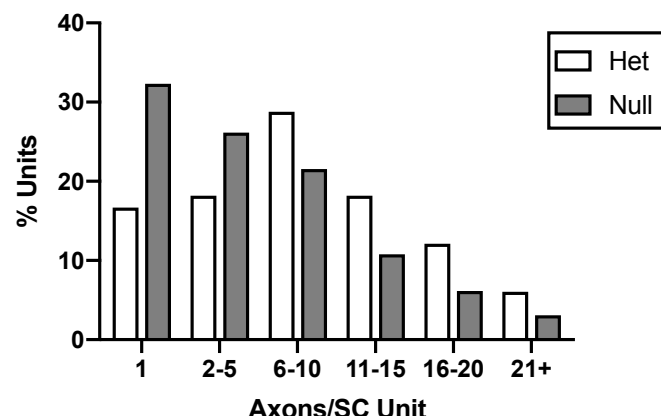

Figure 10: Gli1 expression regulates the morphometry of axonSchwann cell units 


\section{A}

B
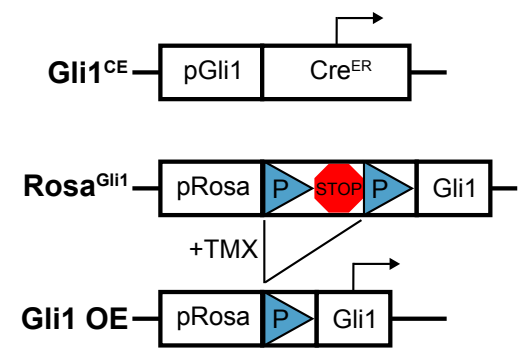

D

Gli1 Het

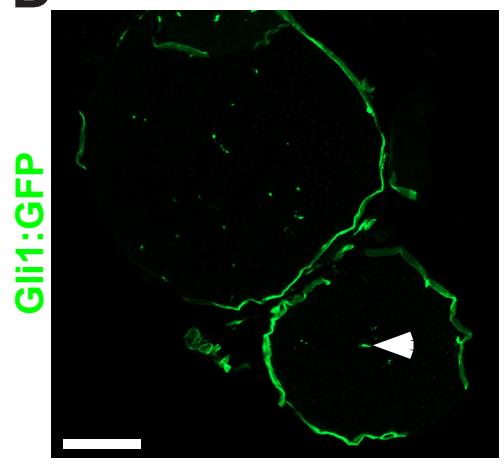

E

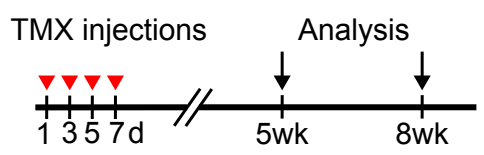

Gli1 Het OE

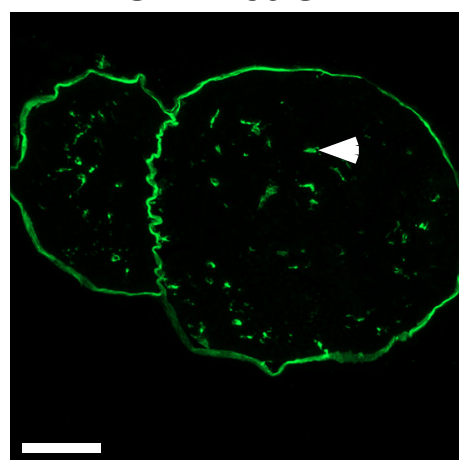

Gli1 Null OE

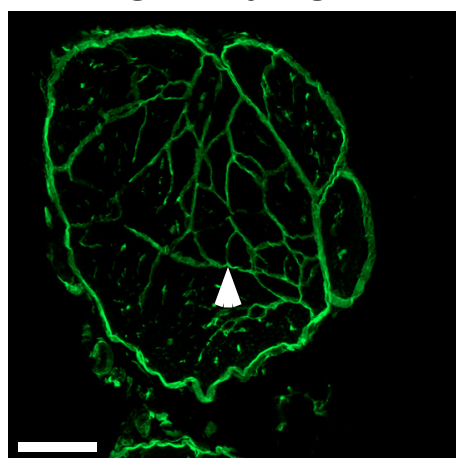

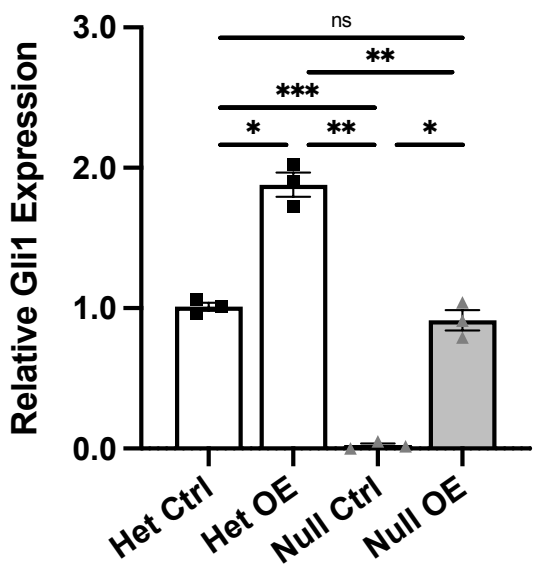

Figure 12: Restoring Gli1 expression in Gli1 nulls does not revert minifascicles 
A Gli1:tdT

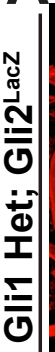

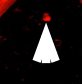

B

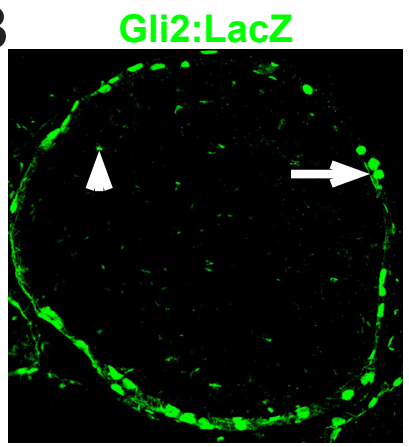

Merge DAPI

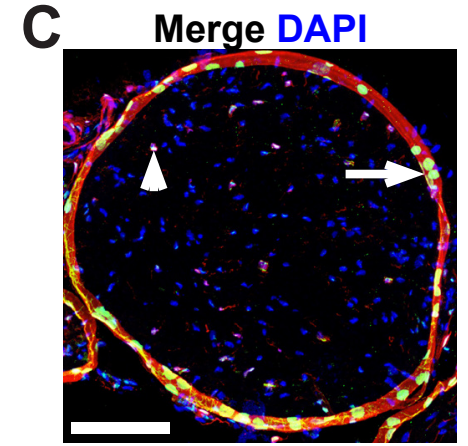

\section{Extended Data Figure 1: Gli2 is expressed in Gli1 fate mapped cells in the PNS}


